\title{
Triazaspirodimethoxybenzoyls as selective inhibitors of mycobacterial lipoamide dehydrogenase ${ }^{\dagger, \#}$
}

\author{
Ruslana Bryk $\ddagger$, Nancy Arango§, Aditya Venugopal ${ }^{\ddagger}, \perp$, J. David Warren $\|$, Yun-Hee Park $\llbracket$, \\ Mulchand S. PatelI, Christopher D. Lima $§,{ }^{*}$, and Carl Nathan $\ddagger, \perp,{ }^{*}$ \\ ‡ Department of Microbiology \& Immunology, Weill Cornell Medical College, New York, NY 10065 \\ |l Department of Biochemistry, Weill Cornell Medical College, New York, NY 10065 \\ $\S$ Structural Biology Program, Sloan-Kettering Institute, New York, NY 10065 \\ ${ }^{\perp}$ Program in Immunology and Microbial Pathogenesis, Weill Graduate School of Medical Sciences \\ of Cornell University, New York, NY 10065 \\ I Department of Biochemistry, School of Medicine and Biomedical Sciences, University at Buffalo, \\ The State University of New York, Buffalo, NY 14214
}

\begin{abstract}
Mycobacterium tuberculosis (Mtb) remains the leading single cause of death from bacterial infection. Here we explored the possibility of species-selective inhibition of lipoamide dehydrogenase (Lpd), an enzyme central to Mtb's intermediary metabolism and antioxidant defense. High-throughput screening of combinatorial chemical libraries identified triazaspirodimethoxybenzoyls as highnanomolar inhibitors of Mtb's Lpd that were noncompetitive versus NADH, $\mathrm{NAD}^{+}$, and lipoamide and $>100$-fold selective compared to human Lpd. Efficacy required the dimethoxy and dichlorophenyl groups. The structure of an Lpd-inhibitor complex was resolved to $2.42 \AA$ by X-ray crystallography, revealing that the inhibitor occupied a pocket adjacent to the Lpd NADH/NAD ${ }^{+}$ binding site. The inhibitor did not overlap with the adenosine moiety of NADH/NAD ${ }^{+}$but did overlap with positions predicted to bind the nicotinamide rings in $\mathrm{NADH}$ and $\mathrm{NAD}^{+}$complexes. The dimethoxy ring occupied a deep pocket adjacent to the FAD flavin ring where it would block coordination of the NADH nicotinamide ring, while the dichlorophenyl group occupied a more exposed pocket predicted to coordinate the $\mathrm{NAD}^{+}$nicotinamide. Several residues that are not conserved between the bacterial enzyme and its human homolog were predicted to contribute both to inhibitor binding and species selectivity, as confirmed for 3 residues by analysis of the corresponding mutant Mtb Lpd proteins. Thus non-conservation of residues lining the electrontransfer tunnel in Mtb Lpd can be exploited for development of species-selective Lpd inhibitors.
\end{abstract}

\footnotetext{
Most antibiotics with known mechanisms of action target bacterial synthesis of nucleic acids, protein, cell walls or folate (1). The practice of focusing antibiotic development almost solely on these targets may have contributed to a steep decline in the rate of introduction of new antiinfectives, while emergence of drug resistance has continued unabated $(2,3)$. The need to

${ }^{\dagger}$ This work was supported by NIH grants AI064768 and DK080748, the Milstein Program in Chemical Biology of Infectious Diseases and the Milstein Chemistry Core Facility.

${ }^{\#}$ The atomic coordinates and structure factors have been deposited in the Protein Data Bank with the accession code 3II4.

*To whom correspondence should be addressed. C.N.: telephone, 212746 6505; fax, 212746 8587;, cnathan @ med.cornell.edu; C.D.L.: telephone, 212639 8205; fax, 212717 3047;, limac@ mskcc.org.

SUPPORTING INFORMATION

Supplementary Figures are available free of charge via the Internet at http://pubs.acs.org.
} 
identify inhibitors of new bacterial targets is particularly acute in tuberculosis (TB) ${ }^{1}$. TB is second only to HIV as a leading cause of death from infectious disease, and is the leading cause of death in people infected with HIV (4). TB cases resistant to all approved anti-infectives have been reported in 55 countries (5). TB chemotherapy is particularly challenging because therapy is more prolonged than for almost any other bacterial infection. Prolonged therapy is required because some populations of Mtb are phenotypically tolerant to anti-infective agents that target pathways used by replicating Mtb to build biomass. Phenotypic tolerance is believed to arise when some of the bacteria persist in a non-replicative state $(6,7)$.

New approaches have recently emerged in TB drug research. A diarylquinoline that inhibits ATP synthase was the first agent targeting bacterial energy production to enter clinical trials $(8,9)$. This agent is active against both replicating and non-replicating Mtb, suggesting that energy production pathways can be effective targets in elimination of non-replicators (10). The nitroimidazole PA824 kills non-replicating Mtb in part by generating reactive nitrogen species (11) that mimic an element of host immune chemistry (12). This underscores the possible utility of inhibiting Mtb's defenses against oxidative and nitrosative attack by the host $(13,14)$. We recently combined these approaches - that is, targeting both metabolic and detoxification pathways-in identifying inhibitors of Mtb's DlaT (15), a component of Mtb's PDHC (16) and PNR/P $(17,18)$.

Here we have focused on Lpd as another enzyme that subserves both energy generation and defense against oxidative and nitrosative attack. Lpd (EC 1.8.1.4) belongs to a family of pyridine nucleotide:disulfide oxidoreductases and catalyzes flavin-dependent regeneration of the lipoamide cofactor involved in production of reducing equivalents in the form of a reduced cofactor (NADH). Lpd is a common component of eukaryotic and prokaryotic $\alpha$-ketoacid dehydrogenase complexes, including PDHC, KGDHC, BCKADHC and the GCS. As the E3 component of PDHC, KGDHC or BCKADHC complexes or the L-protein of the GCS, Lpd re-oxidizes the lipoamide covalently attached to the $\varepsilon$-amino group of the active site lysine of the E2 components of $\alpha$-ketoacid dehydrogenase complexes or the H-protein of the GCS and generates NADH. Each of these complexes functions at a critical commitment or regulatory step in intermediary metabolism.

Mtb's single functional Lpd is encoded by Rv0462 (19). The Mtb enzyme is a component of PDHC (16) but Mtb lacks KGDHC (20) and until recently no BCKADHC or GCS activities have been demonstrated in mycobacteria. Evidence that Mtb Lpd participates in BCKADHC will be presented elsewhere (Venugopal, A., R. Bryk, S. Ehrt, K. Rhee and C. Nathan, ms in preparation). Unlike Lpd from other species, Mtb Lpd is directly involved in protection against reactive nitrogen and reactive oxygen intermediates (18) as a component of an NADHdependent PNR/P. The PNR/P complex also contains DlaT, the lipoamide-containing E2 component of PDHC; a thioredoxin-like protein specific to mycobacteria, termed AhpD; and the peroxiredoxin AhpC. As a component of PDHC, Lpd generates NADH via simultaneous oxidation of the lipoamide of DlaT. The PNR/P reaction proceeds in the opposite direction and Lpd uses NADH to reduce DlaT's lipoamide and transfer reducing equivalents to AhpD's active site Cys and subsequently to regenerate reduced AhpC, which directly breaks down peroxynitrite and peroxides. Thus mycobacterial Lpd uniquely links NADH-dependent metabolic and antioxidant pathways.

\footnotetext{
${ }^{1}$ Abbreviations: Mtb, Mycobacterium tuberculosis; Lpd, lipoamide dehydrogenase; TB, tuberculosis; HIV, human immunodeficiency virus; PDHC, pyruvate dehydrogenase complex; PNR/P, peroxynitrite reductase/peroxidase; KGDHC, $\alpha$-ketoglutarate dehydrogenase complex; BCKADHC, branched chain ketoacid dehydrogenase complex; GCS, glycine cleavage system; DlaT, dihydrolipoamide acyltransferase; AhpD, alkyl hydroperoxide reductase subunit D; DTNB, 5,5'-dithiobis-2-nitrobenzoic acid; OD, optical density.
} 
Mycobacteria lacking DlaT showed a delayed growth phenotype in vitro on carbohydrates as carbon source, were more susceptible to nitrosative stress than wild-type, and persisted in mouse lungs at $\sim 1.5-\log _{10}$ lower levels than the wild-type, causing little histopathologic evidence of disease (21). Deficiency of Lpd imposes a much more severe phenotype on Mtb than deficiency of DlaT (Venugopal, A., R. Bryk, S. Ehrt, K. Rhee and C. Nathan, ms in preparation). Thus, we reasoned that Mtb Lpd could be a better target than Mtb DlaT, provided that inhibitors of Mtb Lpd spare Lpd of the host. Although nonessential for in vitro growth of mycobacteria, both $\Delta d l a T$ and $\Delta l p d \mathrm{Mtb}$ display an attenuated phenotype in vivo. Most striking, mice infected with $\Delta l p d$ Mtb show no evidence of disease. Thus while target validation is conventionally based on in vitro essentiality, we would argue that essentiality during infection of the host is the relevant criterion. The crystal structure of Mtb's Lpd (22) revealed active site differences between Mtb Lpd and human Lpd that might permit selective inhibition.

Here we present identification, characterization and limited structure activity relationship analysis of triazaspirodimethoxybenzoyls as potent, selective inhibitors of Mtb Lpd and report the co-crystal structure of Mtb Lpd with $N$-(2,4-dichlorophenethyl)-2-(8-(2,4-

dimethoxybenzoyl)-4-oxo-1-phenyl-1,3,8-triazaspiro[4.5]decan-3-yl)acetamide (compound 5).

\section{EXPERIMENTAL PROCEDURES}

\section{Materials}

Bovine Lpd and porcine PDHC were from Sigma. 3-(4,5-dimethylthiazol-2-yl)-5-(3carboxymethoxyphenyl)-2-(4-sulfophenyl)-2H-tetrazolium assay reagents were from Promega. QuikChange Site-Directed Mutagenesis Kits were from Stratagene. NADH, DTNB, thiamine pyrophosphate, pyruvate and all other reagents were from Sigma.

\section{Proteins}

Recombinant Mtb Lpd, DlaT, AhpD and AceE were expressed without fusion tags in E. coli and purified as published $(16,18,19)$. Native bovine liver thioredoxin reductase was purified from calf liver as reported (23).

\section{Overexpression and purification of human Lpd}

Five mL overnight culture of $E$. coli M15 cells containing plasmid pDMI.1 and pQE-9-E3 (Lpd) expression vector was used to inoculate a liter of LB medium containing ampicillin (100 $\mu \mathrm{g} / \mathrm{ml})$ and kanamycin $(25 \mu \mathrm{g} / \mathrm{ml})$. Cells were grown to an optical density of 0.7 and induced with isopropyl- $\beta$-D-thiogalactopyranoside $(200 \mu \mathrm{g} / \mathrm{ml})$ at $25^{\circ} \mathrm{C}$ overnight. The cells were harvested by centrifugation at $6000 \mathrm{~g}$ for $30 \mathrm{~min}$ at $4^{\circ} \mathrm{C}$ and the cell pellets were resuspended in $50 \mathrm{mM}$ sodium phosphate ( $\mathrm{pH} 8.0$ ) containing $200 \mathrm{mM} \mathrm{NaCl}$. Lysozyme was added to a final concentration of $1 \mathrm{mg} / \mathrm{ml}$ and the suspension was incubated on ice for $30 \mathrm{~min}$ with occasional stirring. The cells were lysed in a French press (500 psi). Unbroken cells and debris were removed by centrifugation at $20000 \mathrm{~g}$ for $30 \mathrm{~min}$. The supernatant was applied to a $\mathrm{Ni}$ nitrilotriacetic-agarose column. Lpd was eluted by a linear 30-150 $\mathrm{mM}$ imidazole gradient in $50 \mathrm{mM}$ sodium phosphate ( $\mathrm{pH}$ 8.0) containing $200 \mathrm{mM} \mathrm{NaCl}$. Fractions containing human Lpd were dialyzed against $50 \mathrm{mM}$ sodium phosphate buffer ( $\mathrm{pH} 8.0)$ and stored at $-80^{\circ} \mathrm{C}$ (24). Human Lpd was $\sim 95 \%$ pure as judged by densitometry of sodium dodecyl sulfate polyacrylamide gel electrophoresis.

\section{Preparation of D, L-dihydrolipoamide}

D, L-6, 8-Thioctic acid (200 mg) was dissolved in $5 \mathrm{ml}$ of methanol-water mixture (4:1, v/v) at $50^{\circ}$ C. After solublization, $1 \mathrm{ml}$ of ice-cold sodium borohydride $(200 \mathrm{mg} / \mathrm{ml}$ in water) was 
added and stirred for $1-2 \mathrm{~h}$ on ice (25). The solution was adjusted to $\mathrm{pH} 1.0-2.0$ with $1 \mathrm{M} \mathrm{HCl}$. The reduced compound was extracted with an equal volume of chloroform by shaking. The chloroform phase (lower layer) was transferred to a new container. This extraction procedure was repeated twice and chloroform was evaporated using a Speed-Vac with heat. The white residue was resuspended with $10 \mathrm{ml}$ of benzene and then $4 \mathrm{ml}$ of n-hexane was added immediately. The precipitate was collected by filtering through $3 \mathrm{MM}$ paper and dried under vacuum. D, L- dihydrolipoamide was stored at $-20^{\circ} \mathrm{C}$ with protection from light (26).

\section{High-throughput screening}

Screening was conducted in the Rockefeller University-Weill Medical College High Throughput Screening Resource Facility using 80,000 compounds purchased from ChemDiv, Cerep, Spectrum and Albany Molecular Research, Inc. As this collection grew, filters were applied for compounds with drug-like properties and lack of functionalities likely to promote non-specific reactivity. Inhibition of DTNB reduction was assessed in Falcon Microtest 384well plates with a capacity of $30 \mu \mathrm{l}$ per well. Lpd alone or together with DlaT and AhpD was dispensed in $10 \mu \mathrm{l}$ by a Matrix Wellmate plate filler. Compounds were added by a single dip $(100 \mathrm{nl})$ with a Minitrak fluidics robot. Plates were incubated on a shaker for $30 \mathrm{~min}$ at room temperature. Reaction mixture ( $200 \mu \mathrm{M}$ NADH, $150 \mu \mathrm{M}$ DTNB in $100 \mathrm{mM}$ potassium phosphate, $\mathrm{pH}$ 7.0, $2 \mathrm{mM}$ ethylenediaminetetraacetic acid for the Lpd+DlaT+AhpD mixture, or including $150 \mu \mathrm{M}$ lipoamide for assays with Lpd alone) was added in $10 \mu \mathrm{l}$ volumes. The optical density at $405 \mathrm{~nm}$ due to 2-nitro-5-thiobenzoate (TNB) formation during DTNB reduction was recorded on an Envision Multifunction plate reader for 'time 0' values. Plates were incubated on the shaker for $30 \mathrm{~min}$ at room temperature and optical density at $405 \mathrm{~nm}$ recorded again. 'Time 0' values were subtracted from 'time 30 min' values. Activity in control wells containing all components except test compounds was set as $100 \%$. Wells with no protein but with reaction mixture only were used as negative controls. The final concentrations of all components were as follows: Lpd (in complex or alone), $100 \mathrm{nM}$; DlaT, $175 \mathrm{nM}$; AhpD, 18 nM; NADH, $100 \mu \mathrm{M}$; DTNB, $75 \mu \mathrm{M}$; lipoamide (if present), $75 \mu \mathrm{M}$; potassium phosphate, 50 $\mathrm{mM}$; ethylenediaminetetraacetic acid, $1 \mathrm{mM}$; test compounds, $12.5 \mu \mathrm{M}$.

For hit confirmation, compounds were synthesized in house in the Milstein Chemistry Core Facility. Purity was $>95 \%$ as assessed by nuclear magnetic resonance (Bruker DRX-500 spectrometer), high performance liquid chromatography (Waters ACQUITY system), and electrospray ionization mass spectroscopy (Waters Micromass SQ spectrometer).

\section{Enzymatic Assays}

$\mathrm{IC}_{50} \mathrm{~S}$ were determined with serial dilutions ( 100 to $\left.0.1 \mu \mathrm{M}\right)$ of inhibitor by a fluorimetric assay with DTNB, lipoamide and NADH (19) or PDHC assay (16) as described. Human Lpd was assayed by DTNB assay with $10 \mu \mathrm{M}$ lipoamide or dihydrolipoamide- $\mathrm{NAD}^{+}$ spectrophotometric assay. Bovine thioredoxin reductase was assayed with $100 \mu \mathrm{M} \mathrm{NADPH}$ and $75 \mu \mathrm{M}$ DTNB. NADH was detected by absorbance at $340 \mathrm{~nm}$ or fluorescence using a Molecular Devices SpactraMax M5 plate reader. Curves were fitted using IGOR Pro (WaveMetrics, Portland, OR) Version 4.06A Carbon with the Hill equation: $\mathrm{Y}=\mathrm{Ymax} /(1+$ $(\mathrm{IC} 50 /[\mathrm{I}])^{\mathrm{n}}$, where $\mathrm{n}$ is the Hill coefficient. Kinetic parameters were determined by NADHlipoamide fluorimetric assay at variable substrate $(0.2$ to $5 \mathrm{mM}$ lipoamide; 3.33 to $100 \mu \mathrm{M}$ $\mathrm{NADH})$ and increasing inhibitor $(0,0.01,0.1,0.3,0.6,0.9,1.2,2 \mu \mathrm{M})$ concentrations in the presence of $20 \mu \mathrm{M} \mathrm{NAD}{ }^{+}$to relieve inhibition by NADH and obtain hyperbolic plots (19) and by dihydrolipoamide- $\mathrm{NAD}^{+}$spectrophotometric assay at fixed dihydrolipoamide $(1.5 \mathrm{mM})$, variable $\mathrm{NAD}^{+}(25 \mu \mathrm{M}$ to $2.5 \mathrm{mM})$ and increasing inhibitor $(0,1.2,2,4,8 \mu \mathrm{M}) . \mathrm{K}_{\mathrm{m}}$ and $\mathrm{V}_{\max }$ values were determined by fitting the data to a hyperbolic function $\mathrm{V}=\mathrm{V}_{\max } * \mathrm{X} /\left(\mathrm{K}_{\mathrm{m}}+\mathrm{X}\right)$. $\mathrm{K}_{\mathrm{i}}$ values were determined from nonlinear regression analysis in Prism by fitting data to equation for noncompetitive inhibition $\mathrm{V}=\mathrm{V}_{\max } /\left(1+\mathrm{I} / \mathrm{K}_{\mathrm{i}}\right) * \mathrm{X} /\left(\mathrm{K}_{\mathrm{m}}+\mathrm{X}\right)$. 


\section{Mammalian Cell Toxicity}

Mouse bone marrow macrophages were isolated as reported (21), seeded at $5 \times 10^{4}$ cells/well in a 96-well plate and allowed to adhere for $24 \mathrm{~h}$ in Dulbecco's modified Eagle's medium with $4.5 \mathrm{~g} / \mathrm{L}$ glucose, $0.584 \mathrm{~g} / \mathrm{L}$ L-glutamine, $1 \mathrm{mM}$ pyruvate, $10 \%$ fetal bovine serum and $10 \% \mathrm{~L}$ cell conditioned medium. The medium was then replaced with Dulbecco's modified Eagle's medium containing serial dilutions ( $100 \mu \mathrm{M}$ to $45 \mathrm{nM}$ ) of inhibitor. After $24 \mathrm{~h}$, cell viability was assessed by reduction of 3-(4,5-dimethylthiazol-2-yl)-5-(3- carboxymethoxyphenyl)-2(4-sulfophenyl)-2H-tetrazolium according to the manufacturer's instructions.

\section{Site-directed Mutagenesis}

Site-directed mutagenesis was performed using QuikChange kit. The following primers were used with the QuikStart MultiSite kit: 5'GCCGGAGCTGGTGTAATTGGCATGGAGTTC3' (A181V); 5'CCGACCGCAAG AGAATCGGTGTCGACG3'(A290R); 5'

CGGATGTTGCCGTCAGTGACGTTCT GTCAGCC3' (R347S A348V). The rest of the mutant Mtb Lpd proteins were made using the traditional QuikStart kit with the following primers: forward 5'ACCGGCAGTAGCACCACTCTGGTTCCCGGCACC'3 and reverse 5' AGGTGCCGGGAACCAGAGTGGTGCTACTGCCGG3' (R147T); forward 5' CGGGCGCTGCCCGTTGAGGACGCCGATGTGTCC 3' and reverse 5' TTGGACACATCGGCGTCCTCAACGGGCAGCGCCCG3' (N209V); forward 5' TTCCGCGGGCGCTGCCCGTTATTGACGCCGATGTGTCCAAGGAG3' and reverse 5' CTTGGACACATCGGCGTCAATAACGGGCAGCGCCCGCGGAAGG3' (N209V E210I); forward 5'

GCTATCGGCGATGTCAATGCTGGTCCAATGCTGGCGCACGTCGCCGAGGC3' and reverse $5^{\prime}$ GCCTCGGCGACGTGCGCCAGCATTGGACCAGCATTGACATCGCCGATAGC3' (G312A L313G L314P Q315M); forward 5' ATGTCAATGGATTACCACAGCTGGCGCACGTCGCCG3' and reverse 5' CGGCGACGTGCGCCAGCTGTGG TAATCCATTGACAT3' (L314P); forward 5' ACCATCGGATGTTGCCGTCA GCGACGTTCTGTCAGCC3' and reverse 5' GGCTGACAGAACGTCGCTGA CGGCAACATCCATGG3' (R347S); forward 5' AAGGTGTTGCAGGCCATCGGACGA GCGCCCAACGTC3' and reverse 5' GACGTTGGGCGCTCGTCCGATGGCCTG CAACACCTT3' (F269R). Mutant proteins were expressed and purified as for wild-type Mtb Lpd (19).

Lysates were prepared as described (18) and protein determined by the Bradford method.

\section{Cloning, expression and protein purification for crystallographic analysis}

Mtb $l p d C$ (Rv0462)-(1-464) was amplified by polymerase chain reaction, cloned, into a modified pET28b vector containing N-terminal hexahistidine-tagged $S$. cerevisiae Smt 3 and used to transform E. coli BL21 (DE3) Codon Plus RLI (Novagen) as reported (22). A 6 liter culture was fermented at $37^{\circ} \mathrm{C}$ to an optical density of 0.8 at $600 \mathrm{~nm}$, induced by addition of isopropyl- $\beta$-D-thiogalactopyranoside to a final concentration of $1 \mathrm{mM}$, then fermented at $30^{\circ}$ $\mathrm{C}$ for 4 hours. Cells were harvested by centrifugation and suspended in $50 \mathrm{mM}$ Tris- $\mathrm{HCl}(\mathrm{pH}$ 8.0), $20 \% \mathrm{w} / \mathrm{v}$ sucrose, $350 \mathrm{mM} \mathrm{NaCl}, 20 \mathrm{mM}$ imidazole, $0.1 \%$ tert-Octylphenoxy poly (oxyethylene)ethanol, $1 \mathrm{mM}$ phenylmethylsulphonyl fluoride, $1 \mathrm{mM} \beta$-mercaptoethanol, and $10 \mu \mathrm{g} / \mathrm{ml}$ DNAse prior to sonication. Cell debris was removed by centrifugation. Protein was purified from the supernatant using Ni-NTA-agarose resin (Qiagen) and gel filtration (Superdex 200). The $\mathrm{His}_{6}-\mathrm{Smt} 3 \mathrm{tag}$ was liberated from Mtb Lpd by incubation with the Smt3 protease Ulp (403-621) (27) and the two proteins were separated by gel filtration (Superdex 200). Fractions containing Mtb Lpd were buffer exchanged into $20 \mathrm{mM}$ Tris pH 8.0, $87.5 \mathrm{mM}$ $\mathrm{NaCl}$ and $1 \mathrm{mM} \beta$ - mercaptoethanol, concentrated to $10 \mathrm{mg} / \mathrm{ml}$, aliquoted, flash frozen in liquid nitrogen and stored at $-80^{\circ} \mathrm{C}$. 


\section{Crystallization and structure determination}

Two hundred $\mu \mathrm{M}$ Mtb Lpd (1-464), $300 \mu \mathrm{M}$ compound 5 and $600 \mu \mathrm{M}$ NADH were mixed and incubated on ice for $10 \mathrm{~min}$. Crystals were grown at $18^{\circ} \mathrm{C}$ by hanging drop vapor diffusion against a well solution containing $100 \mathrm{mM}$ Tris $\mathrm{pH} 8.5,10 \mathrm{mM} \mathrm{NaCl}, 11 \%$ polyethylene glycol $10,000(\mathrm{w} / \mathrm{v}), 15 \%$ ethylene glycol $(\mathrm{v} / \mathrm{v})$. Crystals were further cryo-protected by transfer to crystallization solutions containing the well solution with the addition of $25 \%$ ethylene glycol. Crystals were flash-cooled in liquid nitrogen. A single crystal was diffracted and data collected using a Rigaku RU200 X-ray generator equipped with confocal Osmic multilayer optics and Raxis-IV imaging plate detector. A complete data set was obtained at $2.42 \AA$ and reduced with DENZO, SCALEPACK, and CCP4 [Table $1 ;(28,29)]$. The same crystal was diffracted at the NE-CAT beamline $24-I D C$ at $0.9795 \AA$ although no improvement in data quality was observed (not shown). The structure of Lpd bound to compound $\mathbf{5}$ was determined by molecular replacement using programs contained within CCP4 and our previously determined structure of Lpd (22). The crystal included one dimer in the asymmetric unit and a model comprising Lpd amino acids 2-464 and 1-464 was refined after addition of 484 water molecules to an R/ Rfree of $0.21 / 0.27$ at $2.42 \AA$ using CNS (30). A model for compound 5 was constructed using Chemdraw 3D and modeled using O (31) into 2fo-fc and fofc electron density (Supplemental Fig. 1). Stereochemical restraints for the model were modified based on the electron density and the final model was refined at $2.42 \AA$ to an R/Rfree of $0.19 / 0.24$ (Table 1). The model has excellent geometry with $89.3 \%$ of residues in most favored, $10.7 \%$ of residues in allowed, and no residues in generous or disallowed regions of the Ramachandran plot. The atomic coordinates and structure factors have been deposited in the Protein Data Bank with the accession code 3II4.

\section{RESULTS}

\section{Identification of triazaspirodimethoxybenzoyls}

We screened more than 80,000 compounds using pure, recombinant, non-tagged Mtb Lpd alone or in combination with pure, recombinant, non-tagged DlaT and AhpD (Fig. 1). The screening was done by DTNB reductase assay wherein the generation of a yellow TNB product from DTNB occurs via sequential transfer of reducing equivalents from NADH via Lpd either to lipoamide (when Lpd singularly was used in the assay) or to DlaT to reduce its covalently attached lipoamide and then to the AhpD active site Cys. Either reduced lipoamide or reduced AhpD directly reduces DTNB to produce TNB. A set of 15,000 compounds from ChemDiv was screened using the 3-component protein mixture. Fourteen inhibitors were confirmed to inhibit Lpd when re-tested using Lpd alone. However, these were non-specifically reactive in that they also inhibited thioredoxin reductase and were toxic to mammalian cells. It was then discovered that they underwent hydrolysis to maleimides. The remaining compounds from ChemDiv, Cerep, Spectrum and Albany Molecular Research, Inc. were screened using Lpd alone. From the Spectrum library ten inhibitors that had nanomolar to low micromolar $\mathrm{IC}_{50} \mathrm{~s}$ against Mtb Lpd were identified, but they proved to be toxins such as phenylmercuric acetate, thimerosal, merbromin, hexachloropene and cisplatin. Because screening of the first 20,000 compounds with a criterion of $75 \%$ inhibition only identified redox- active and/or toxic compounds, we reduced the cut-off to $25 \%$ inhibition at $12.5 \mu \mathrm{M}$. With this criterion, the Albany Molecular Research, Inc. collection yielded 50 inhibitors ( $0.1 \%$ hit rate), of which 42 (84\%) were confirmed upon re-testing. Fifteen of these compounds inhibited Mtb Lpd with $\mathrm{IC}_{50} \mathrm{~s}<50 \mu \mathrm{M}$. The most potent were triazaspirodimethoxybenzoyls, whose activity was confirmed upon re-supply, and for compound $\mathbf{5}$, described below, upon re-synthesis in-house.

The most potent inhibitor, $N$-(2,4-dichlorophenethyl)-2-(8-(2,4-dimethoxybenzoyl)-4- oxo-1phenyl-1,3,8-triazaspiro[4.5]decan-3-yl)acetamide (compound 5) (Fig. 2A) had an $\mathrm{IC}_{50}$ of 1 $\mu \mathrm{M}\left(\mathrm{K}_{\mathrm{i}}=865 \pm 41 \mathrm{nM}\right)$ against Mtb Lpd and did not produce any measurable inhibition of 
human Lpd at concentrations up to $100 \mu \mathrm{M}$ (Fig. 2, $B$ and $C$ ). The structurally related inhibitor 2-(8-(2,4-dimethoxybenzoyl)-4-oxo-1-phenyl-1,3,8-triazaspiro[4.5]decan-3-yl)- $N$-(3(trifluoro methyl)benzyl) acetamide (compound 4) had an $\mathrm{IC}_{50}$ of $2 \mu \mathrm{M}$ against Mtb Lpd and did not inhibit human Lpd at concentrations up to $100 \mu \mathrm{M}$ (Table 2). Compounds 5 and $\mathbf{4}$ also inhibited Mtb Lpd in an NADH-lipoamide assay, a dihydrolipoamide-NAD ${ }^{+}$assay and a PDHC assay in complex with AceE and DlaT, the E1 and E2 components of the PDHC. No inhibition of human Lpd at concentrations up to $100 \mu \mathrm{M}$ was observed in the physiological direction of the reaction with dihydrolipoamide and NAD ${ }^{+}$as substrates. Both compounds 5 and 4 efficiently inhibited Lpd activity in Mtb extracts with $\mathrm{IC}_{50}$ in the low micromolar range as measured by inhibition of PDHC activity (Fig. 2D). Moreover, potency was unaffected in the presence of bovine serum albumin $(100 \mu \mathrm{g} / \mathrm{mL})$ (Fig. 2B). Both compounds displayed minimal activity with $\mathrm{IC}_{50} \mathrm{~s} \sim 100 \mu \mathrm{M}$ against bovine thioredoxin reductase, a redox enzyme belonging to the same family as $\mathrm{Lpd}$, and affected mouse bone marrow macrophage survival only at the limit of solubility (100 $\mu \mathrm{M} ; 80 \%$ survival) (Fig. 2C). Triazaspirobenzoyls structurally similar to compounds 5 and $\mathbf{4}$ but lacking one or two methoxy groups were inactive against Lpd and served as negative controls (Fig. 2, Table 2).

The mode of action of compound $\mathbf{5}$ was probed by varying the concentration of substrate $\left(\mathrm{NADH}, \mathrm{NAD}^{+}\right.$, or lipoamide) and inhibitor. The data suggested that compound $\mathbf{5}$ is noncompetitive with respect to NADH, $\mathrm{NAD}^{+}$and lipoamide (Fig. 3).

We screened over 300 triazaspiro compounds at $12.5 \mu \mathrm{M}$. The vast majority (>220) gave no inhibition of Mtb Lpd activity; 60 produced minimal (5-10\%) inhibition; and 20 afforded inhibition in the range of 10-70\%. Comparison of their structures revealed structure-activity relationships. Congeners lacking one or two methoxy groups were inactive (Table 3).

Replacement of both methoxy groups by other groups such as trifluoromethyl led to loss of activity. Triazaspirodimethoxybenzoyls lacking the dichlorophenyl ethyl arm were inactive. Addition of a third methoxy to the latter compounds restored some activity, but had no effect when added to compound $\mathbf{5}$. Substitution of the dichlorophenyl ethyl with shorter substructures decreased activity; conversely, longer and bulkier groups produced better inhibition. Thus, both dimethoxybenzoyl and dichlorophenyl (trifluoromethylphenyl in compound 4) groups appeared to be essential for inhibition of Mtb Lpd (Table 3). Intolerance to most substitutions suggested that the effective inhibitors engaged in specific, multi-point interactions with Mtb Lpd, indicative of binding in a protein pocket. Thus, we next sought to co-crystallize Mtb Lpd with compound $\mathbf{5}$.

\section{Structure of the Lpd-compound 5 complex}

The protein component of the Mtb Lpd structure resembled that previously determined for Mtb Lpd in the absence of compound $\mathbf{5}$ with one Lpd dimer or two Lpd protomers in the crystallographic asymmetric unit (22). One inhibitor was observed in each Lpd protomer in a deep pocket adjacent to the FAD flavin ring and NADH/NAD ${ }^{+}$binding pocket (Fig. 4).

Although $600 \mu \mathrm{M} \mathrm{NADH}$ was present in the crystallization and cryopreservation buffers, no NADH was observed in the structure, consistent with the binding of compound $\mathbf{5}$ (see below). The binding site occupied by compound $\mathbf{5}$ is proximal to the NAD+/NADH binding site and opposite the FAD ring with respect to the lipoamide binding site and active site cysteine residues (Cys41 and Cys46), which were observed in the oxidized, disulfide-bonded configuration.

Compound 5 spans $\sim 20 \AA$ from the base of the dimethoxybenzoyl ring to the dichlorophenyl ring (Fig. $4 A$ ) and buries approximately $1300 \AA^{2}$ of total surface area in each of the two Lpd binding sites. The dimethoxybenzoyl ring is next to the FAD flavin ring and the oxygen from the proximal methoxy group is within $3.1 \AA$ from the $\mathrm{C} 4$ carbon of the flavin ring. The terminal carbon of the same methoxy group is also $3.1 \AA$ from a carboxylate oxygen from Glu185. 
Additional interactions with the dimethoxy ring include van der Waals contacts between the dimethoxybenzoyl ring and side chain atoms from Leu316 and Ala181. The carbonyl oxygen atom adjacent to the dimethoxybenzoyl ring makes two water mediated hydrogen bonds to the backbone amide atoms of amino acid residues Ala181 and Ile182, respectively (Fig. 4B).

Interactions with the triazaspirophenyl core include van der Waals contacts between the phenyl ring and side chain atoms from amino acid residues Asn209, Glu210, and Arg347 (Fig. 4B). Of these, the Arg347 aliphatic side chain and guanidinium group make the most extensive interactions with the phenyl ring of the triazaspirophenyl core. The carbonyl oxygen of the triazaspirophenyl core is also within hydrogen bonding distance $(3.1 \AA)$ to the backbone amide nitrogen of Gln315 (Fig. 4A).

Several interactions were also observed between the protein and dichlorophenyl ring, including contacts to the linker between the triazaspirophenyl core and dichlorophenyl ring (Fig. 4A). Electron density was notably weaker for the dichlorophenyl ring in both Lpd protomers (Supplemental Fig. 1). In addition, the dichlorophenyl ring was observed in distinct conformations in each of the Lpd protomers (Fig. 4, $C$ and $D$ ). In conformer 1 in Lpd protomer A, the carbonyl oxygen of amino acid residue Gly312 is within hydrogen bonding distance of the amide nitrogen in the linker between the triazaspirophenyl core and dichlorophenyl ring (Fig. 4, $A$ and $C$ ). This contact was not observed in the conformer 2 (Fig. D). Protein interactions to the dichlorophenyl ring include van der Waals contacts with side chain atoms from Ala270, Pro271, Ala290, Arg147, and Arg288. The two conformations observed for the dichlorophenyl ring are accompanied by changes in the conformations of Arg147 and Arg288 in the two complexes (Fig. 4, $C$ and $D$ ). The differences in dichlorophenyl ring conformations observed in the respective Lpd promoter might relate to differences in contacts to Lpd that are proximal to each binding site. The region of the Lpd structure around the binding site for compound 5 conformer 1 is fully exposed to solvent and not involved in lattice contacts, and while the region around the binding site of compound $\mathbf{5}$ conformer 2 is solvent exposed, residues proximal to this binding site are near contacts to a symmetry mate that involves water mediated lattice contacts to Asp287 and Lys 289 and a direct lattice contact to a symmetry mate involving the Glu274 side chain. While these interactions do not involve residues that directly interact with compound $\mathbf{5}$, additional contacts proximal to the ligand binding site might contribute to the conformation observed for compound $\mathbf{5}$ in this binding pocket.

The structure activity relationships described above are consistent with the interactions observed in our crystal structure. One of the two methoxy groups of the dimethoxybenzoyl ring is within van der Waals distance of the flavin ring consistent with the observation that congeners lacking one or two methoxy groups were inactive. The two conformations observed for the dichlorophenyl ring and accompanying changes in conformations for $\operatorname{Arg} 147$ and Arg288 are consistent with the ability to substitute the dichlorophenyl ring in compound $\mathbf{5}$ with the trifluoromethylphenyl ring in compound 4. It is also consistent with the observation that substitution of the dichlorophenyl ethyl moiety with shorter substructures decreased activity; conversely, longer and bulkier groups produced better inhibition.

\section{Compound 5 partially occludes surfaces important for interaction with the nicotinamide ring of NAD}

The surface pocket occupied by compound 5 partially overlaps with $\mathrm{NAD}^{+}$and NADH cofactors as observed in complexes with human Lpd (Fig. 5; (32)). In the human Lpd structures the adenosine monophosphate moiety of NAD occupies an exposed pocket comprised by side chains from Phe209, Glu208, Ile278, and Val243, which interact with the adenosine moiety while the monophosphate is coordinated by several backbone amide atoms (Fig. 5A). The side chain and main chain composition of this binding site are strictly conserved with the Mtb Lpd enzyme (Phe202, Glu201, Ile267, and Val235; (22)). In the human Lpd structures the 
complexes differ, however, in the positions of the second phosphate and nicotinamide rings, depending on whether the enzyme is bound to $\mathrm{NAD}^{+}$or NADH. In the NADH complex (Fig. $5, B$ and $C$ ), the second phosphate and nicotinamide ring penetrate into a deep pocket to stack the nicotinamide ring over the flavin ring in a configuration suitable for hydride transfer. In the NAD+ complex (Fig. 5, $A$ and $D$ ), the second phosphate and nicotinamide ring occupy a solvent exposed pocket. Superposition of the two human Lpd structures with our structure of the Mtb Lpd complex reveals that compound 5 would not occlude interactions with the surfaces involved in binding the NAD adenosine monophosphate moiety, but it would occlude surfaces predicted to be important for interactions with the nicotinamide ring in both $\mathrm{NAD}^{+}$and NADH complexes. As discussed above, compound 5 exhibited non-competitive inhibition with NADH and $\mathrm{NAD}^{+}$. Our structure and superimposition of $\mathrm{NADH}$ and $\mathrm{NAD}^{+}$suggest that compound 5 binds within the NADH/NAD ${ }^{+}$pocket. Thus, competitive behavior might be expected with respect to NADH/NAD ${ }^{+}$. However, since Lpd catalysis proceeds via a bisubstrate Ping Pong Bi Bi mechanism $(33,34)$, both competitive and noncompetitive inhibition patterns can be predicted (35) depending at which site and to which enzyme form the inhibitor will be binding. Lpd catalysis proceeds through two sequential steps of binding and release of products, while the enzyme oscillates between two forms, the reduced form with an $\mathrm{NAD}^{+}$binding site and the oxidized form with an NADH binding site (Supplemental Fig. 2). An inhibitor combining exclusively with either the $\mathrm{NAD}^{+}$or NADH binding site will be predicted to produce competitive kinetics with respect to the substrate of that site. However, an inhibitor that binds both $\mathrm{NAD}^{+}$and NADH sites is expected to produce a non-competitive pattern of inhibition versus both substrates, as predicted by Cleland (35). Thus, although a competitive pattern of inhibition against $\mathrm{NAD}^{+} / \mathrm{NADH}$ substrates may be expected from an inhibitor whose binding site overlaps partially with the $\mathrm{NAD}^{+} / \mathrm{NADH}$ site, its binding to both forms of the enzyme will result in the production of dead-end unproductive enzyme-inhibitor complexes for both forms. The resulting decrease in enzyme available to participate in catalysis will be manifested through a decrease in apparent $\mathrm{V}_{\max }$ and the inability of an infinitely high substrate concentration to overcome the inhibition, thus leading to a non-competitive inhibition pattern as observed.

\section{Analysis of mutant Lpd proteins}

Mutational analysis underscored the importance of contacts observed in the crystal structure and explained why compound $\mathbf{5}$ is a species selective inhibitor of the Mtb Lpd enzyme. Our structural analysis confirmed that compound $\mathbf{5}$ makes multiple close contacts to main chain and side chain atoms within the Lpd active site pocket that were predicted to bind the nicotinamide ring of the $\mathrm{NAD}^{+} / \mathrm{NADH}$ co-factor. Alignment of the Mtb and human Lpd protein crystal structures $(22,32)$ showed that several amino acids in Mtb Lpd that contact the inhibitor are not conserved between the mycobacterial enzyme and its human homolog (Fig. 5), although these residues are conserved among mammalian homologs (porcine and bovine Lpds). This prompted us to explore whether these amino acids may be responsible for the selectivity of compound $\mathbf{5}$ for the bacterial enzyme over its mammalian counterparts. We successfully produced 8 recombinant mutant Mtb Lpd proteins (R147T; A181V; N209V; F269R; A290R; G312A L313G L314P Q315M; L314P; R347S), in which one or multiple residues of the mycobacterial Lpd were substituted by the corresponding residues of the human protein. The recombinant mutant Mtb Lpd proteins had $\mathrm{V}_{\max }$ and $\mathrm{K}_{\mathrm{m}}$ values comparable to wild-type in the absence of compound $\mathbf{5}$. We were unable to purify 4 additional mutant proteins (N209V E210I; E210I; R347S A348V; A348V) because when overexpressed in E. coli, they were retained in the insoluble fraction, suggesting that these substitutions resulted in protein misfolding and/or instability.

We tested the susceptibility of the purified mutant Mtb Lpd proteins to compound $\mathbf{5}$.

Substitution of the mycobacterial residues making contact with or in proximity to dichlorophenyl ring did not critically affect the activity of compound $\mathbf{5}$, in that the $\mathrm{IC}_{50}$ of 
compound 5 was changed only slightly against mutant Lpd proteins R147T, F269R and A290R, from $1 \mu \mathrm{M}$ (for wild-type) to $0.65-2 \mu \mathrm{M}$ (Table 4 ). In contrast, mutation of the mycobacterial residue Ala181 whose side chain is within $3.4 \AA$ of the dimethoxy phenyl ring (Fig. 4B) to the corresponding Val of the human protein nearly abolished activity of compound $\mathbf{5}$, with only $10 \%$ inhibition at $100 \mu \mathrm{M}$. Val is bulkier than Ala, suggesting that human Lpd protein might not be able to accommodate the inhibitor's dimethoxybenzoyl ring.

Mutation of the mycobacterial Leu314 whose side chain is within van der Waals distance of the triazaspirophenyl core (Fig. 4A) also imparted resistance to the inhibitor (Table 4).

However, mutation was tolerated at neighboring residues (G312, L313 and Q315) that made additional contacts with the compound's core, suggesting that substitution of Leu to Pro at this position introduced a more prominent change in the binding pocket. Similarly, substitution of Arg347 by Ser appeared to disrupt contact with the compound's phenyl ring projecting off the triazaspirophenyl core because this mutation conferred resistance to compound $\mathbf{5}$. In contrast, Asn209, despite making multiple contacts with the same phenyl group, could be converted to $\mathrm{Val}$ without conferring resistance to compound $\mathbf{5}$, suggesting that changing the polarity of the contact residue (substitution of Asn209 by Val) does not affect the binding of compound 5 but changing both the polarity and volume of the contact residue (substitution of Arg347 by Ser) produces a more drastic change within the binding pocket.

\section{DISCUSSION}

In the search for new anti-tuberculosis chemotherapy, two approaches of interest are to identify compounds that can inhibit multiple targets, or targets whose inhibition by a single compound can disrupt multiple pathways. There is more experience with the former approach. For example, isoniazid, the cornerstone of tuberculosis chemotherapy, has multiple targets (36). PA-824, a promising agent now in clinical trials, donates reactive nitrogen intermediates (11) that can react with multiple targets in Mtb $(37,38)$.

An example of the second approach — inhibition of one protein in Mtb, thereby disrupting more than one pathway - was perhaps first provided by the identification of species-selective thioxothiazolidines that inhibit Mtb DlaT (15). The present work provides another example, targeting Lpd, an enzyme that shares both of the known functions of DlaT-- in PDHC (16) and PNR/P (18)-- and serves at least one additional function as well-in BCKADHC (Venugopal, A., R. Bryk, S. Ehrt, K. Rhee and C. Nathan, ms in preparation).

Still more functions of bacterial Lpd are possible. While both bacterial and eukaryotic Lpds participate at major commitment steps of intermediary metabolism by regenerating the lipoamide cofactor covalently attached to the E2 subunit of $\alpha$-ketoacid dehydrydogenase complexes, Lpd in some bacteria has been implicated in galactose transport and $\alpha$-galactoside metabolism (39) or found to be secreted and taken up by the host cell, where it may contribute to arrest of phagosome maturation (40). Archaea lack $\alpha$-ketoacid dehydrydogenase complexes, yet still express Lpd (41), making it highly likely that certain Lpd homologs serve undiscovered functions. Among bacterial Lpds, mycobacterial Lpd appears to be unique in that it also fulfills an antioxidant function, helping to protect Mtb from reactive nitrogen and reactive oxygen intermediates (18).

Treatment of an infectious disease by targeting Lpd in the pathogen is not a new concept. Chagas' disease, caused by the protozoan Trypanosoma cruzi, was treated for many years with the nitrofuran nifurtimox (Lampit), which serves as a substrate that is cycled by the protozoal Lpd to generate reactive species harmful to the parasite (42). Nifurtimox is still used in the treatment of African sleeping sickness, caused by Trypanosoma brucei. To our knowledge, however, no inhibitors of Lpd have previously been identified. 
The likely impact of inhibiting Lpd in bacteria can be surmised from the phenotype of mutants in which the gene encoding Lpd has been disrupted. The phenotype of Lpd-deficient Mtb will be reported elsewhere (Venugopal, A., R. Bryk, S. Ehrt, K. Rhee and C. Nathan, ms in preparation). Streptococcus pneumoniae deficient in Lpd was able to grow normally in vitro but was avirulent in sepsis and pneumonia models in mice (39). Haemophilus influenzae with a disrupted $l p d$ gene was unable to establish infection in the rat (43). Listeria monocytogenes lacking an enzyme required for lipoylation of Lpd's interaction partner(s) in $\alpha$-ketoacid dehydrydogenase complexes was severely attenuated in mice (44).

Thus, bacterial Lpd is an attractive target for anti-infective agents, provided such agents spare Lpd of the host. Enzymes of intermediary metabolism are generally not considered as candidate targets for anti-infective therapy because of their high conservation throughout evolution. Mycobacterial Lpd is 36\% identical to the human homolog. Our studies demonstrate that it is possible to find species-selective inhibitors of mycobacterial Lpd. Several of the triazaspirodimethoxybenzoyls identified here are at least 100 times better selective for the bacterial enzyme compared to the human enzyme.

Features critical for potency and species selectivity of the triazaspirodimethoxybenzoyls include the dimethoxy substituents. Mutating amino acid residues of Mtb Lpd in contact with the dimethoxy groups to corresponding amino acids of the human enzyme conferred resistance to inhibition by triazaspirodimethoxybenzoyls. Trimethoxy- and dimethoxylated analogs of compound $\mathbf{5}$ were equally potent, suggesting that no additional contacts are made by a third methoxy group within the protein pocket. Moreover, conversion from the Mtb-encoded Leu314 to the human-encoded residue at the corresponding position apparently precluded productive contact with the triazaspirophenyl core of compound $\mathbf{5}$, in that it led to more than a 100 -fold decrease in inhibitory potency. Similarly, mutation of Arg347, which makes contact with the phenyl ring off the triazaspirocycle, to the corresponding Ser of the human protein decreased the potency of compound 5 by more than 100-fold.

Despite this evidence for tight binding of compound 5, the co-crystal of Mtb Lpd with compound $\mathbf{5}$ revealed at least two positions for the dichlorophenyl ring along with compensatory changes in side chain positions of Arg147 and Arg288. While these data suggest some flexibility or plasticity in this region for both the inhibitor and protein, the dichlorophenyl functionality appeared to contribute to inhibition, because its removal resulted in loss of inhibitory potency. Congeners with bulkier groups making closer contact with the protein in this region might improve the affinity or specificity of triazaspirodimethoxybenzoyls for Mtb Lpd.

To our knowledge, the present work is the first to identify inhibitors of Lpd in any species and the first to demonstrate that compounds can inhibit the Lpd of an infectious agent with orders of magnitude greater potency than the Lpd of its host. These results provide encouragement for seeking clinically useful Lpd inhibitors to target one protein serving diverse pathways in Mtb.

\section{Supplementary Material}

Refer to Web version on PubMed Central for supplementary material.

\section{Acknowledgments}

The Department of Microbiology and Immunology is supported by the William Randolph Hearst Foundation. We thank Ouathek Ouerfelli for discussion, Tarun Kapoor (Rockefeller University) for collaboration in the earliest phases of this work and Charles Karan (Rockefeller University High Throughput Screening Resource Facility) for assembling compound collections. We thank the MSKCC X-ray core for use of their facility. 


\section{References}

1. Walsh C. Where will new antibiotics come from? Nat Rev Microbiol 2003;1:65-70. [PubMed: 15040181]

2. Nathan C. Antibiotics at the crossroads. Nature 2004;431:899-902. [PubMed: 15496893]

3. Boucher HW, Talbot GH, Bradley JS, Edwards JE, Gilbert D, Rice LB, Scheld M, Spellberg B, Bartlett J. Bad bugs, no drugs: no ESKAPE! An update from the Infectious Diseases Society of America. Clin Infect Dis 2009;48:1-12. [PubMed: 19035777]

4. WHO. WHO. 2008. http://www.cdc.gov/hiv/resources/factsheets/hivtb.htm\#1

5. Donald PR, van Helden PD. The global burden of tuberculosis--combating drug resistance in difficult times. N Engl J Med 2009;360:2393-2395. [PubMed: 19494214]

6. Levin BR, Rozen DE. Non-inherited antibiotic resistance. Nat Rev Microbiol 2006;4:556-562. [PubMed: 16778840]

7. Warner DF, Mizrahi V. Tuberculosis chemotherapy: the influence of bacillary stress and damage response pathways on drug efficacy. Clin Microbiol Rev 2006;19:558-570. [PubMed: 16847086]

8. Andries K, Verhasselt P, Guillemont J, Gohlmann HW, Neefs JM, Winkler H, Van Gestel J, Timmerman P, Zhu M, Lee E, Williams P, de Chaffoy D, Huitric E, Hoffner S, Cambau E, TruffotPernot C, Lounis N, Jarlier V. A diarylquinoline drug active on the ATP synthase of Mycobacterium tuberculosis. Science 2005;307:223-227. [PubMed: 15591164]

9. Diacon AH, Pym A, Grobusch M, Patientia R, Rustomjee R, Page-Shipp L, Pistorius C, Krause R, Bogoshi M, Churchyard G, Venter A, Allen J, Palomino JC, De Marez T, van Heeswijk RP, Lounis N, Meyvisch P, Verbeeck J, Parys W, de Beule K, Andries K, Mc Neeley DF. The diarylquinoline TMC207 for multidrug-resistant tuberculosis. N Engl J Med 2009;360:2397-2405. [PubMed: 19494215]

10. Koul A, Vranckx L, Dendouga N, Balemans W, Van den Wyngaert I, Vergauwen K, Gohlmann HW, Willebrords R, Poncelet A, Guillemont J, Bald D, Andries K. Diarylquinolines are bactericidal for dormant mycobacteria as a result of disturbed ATP homeostasis. J Biol Chem 2008;283:2527325280. [PubMed: 18625705]

11. Singh R, Manjunatha U, Boshoff HI, Ha YH, Niyomrattanakit P, Ledwidge R, Dowd CS, Lee IY, Kim P, Zhang L, Kang S, Keller TH, Jiricek J, Barry CE 3rd. PA-824 kills nonreplicating Mycobacterium tuberculosis by intracellular NO release. Science 2008;322:1392-1395. [PubMed: 19039139]

12. MacMicking JD, North RJ, LaCourse R, Mudgett JS, Shah SK, Nathan CF. Identification of nitric oxide synthase as a protective locus against tuberculosis. Proc Natl Acad Sci U S A 1997;94:52435248. [PubMed: 9144222]

13. Nathan C, Gold B, Lin G, Stegman M, de Carvalho LP, Vandal O, Venugopal A, Bryk R. A philosophy of anti-infectives as a guide in the search for new drugs for tuberculosis. Tuberculosis (Edinb) 2008;88 (Suppl 1):S25-S33. [PubMed: 18762150]

14. Lin GLD, Sorio de Carvalho LP, Deng H, Tao H, Vogt G, Wu K, Schneider J, Chidawanyika T, Warren JD, Li H, Nathan C. Inhibitors selective for mycobacterial versus human proteasomes. Nature 2009;461:621-626. [PubMed: 19759536]

15. Bryk R, Gold B, Venugopal A, Singh J, Samy R, Pupek K, Cao H, Popescu C, Gurney M, Hotha S, Cherian J, Rhee K, Ly L, Converse PJ, Ehrt S, Vandal O, Jiang X, Schneider J, Lin G, Nathan C. Selective killing of nonreplicating mycobacteria. Cell Host Microbe 2008;3:137-145. [PubMed: 18329613]

16. Tian J, Bryk R, Shi S, Erdjument-Bromage H, Tempst P, Nathan C. Mycobacterium tuberculosis appears to lack alpha-ketoglutarate dehydrogenase and encodes pyruvate dehydrogenase in widely separated genes. Mol Microbiol 2005;57:859-868. [PubMed: 16045627]

17. Bryk R, Griffin P, Nathan C. Peroxynitrite reductase activity of bacterial peroxiredoxins. Nature 2000;407:211-215. [PubMed: 11001062]

18. Bryk R, Lima CD, Erdjument-Bromage H, Tempst P, Nathan C. Metabolic enzymes of mycobacteria linked to antioxidant defense by a thioredoxin-like protein. Science 2002;295:1073-1077. [PubMed: 11799204] 
19. Argyrou A, Blanchard JS. Mycobacterium tuberculosis lipoamide dehydrogenase is encoded by Rv0462 and not by the lpdA or lpdB genes. Biochemistry 2001;40:11353-11363. [PubMed: 11560483]

20. Tian J, Bryk R, Itoh M, Suematsu M, Nathan C. Variant tricarboxylic acid cycle in Mycobacterium tuberculosis: identification of alpha-ketoglutarate decarboxylase. Proc Natl Acad Sci U S A 2005;102:10670-10675. [PubMed: 16027371]

21. Shi S, Ehrt S. Dihydrolipoamide acyltransferase is critical for Mycobacterium tuberculosis pathogenesis. Infect Immun 2006;74:56-63. [PubMed: 16368957]

22. Rajashankar KR, Bryk R, Kniewel R, Buglino JA, Nathan CF, Lima CD. Crystal structure and functional analysis of lipoamide dehydrogenase from Mycobacterium tuberculosis. J Biol Chem 2005;280:33977-33983. [PubMed: 16093239]

23. Holmgren A. Bovine thioredoxin system. Purification of thioredoxin reductase from calf liver and thymus and studies of its function in disulfide reduction. J Biol Chem 1977;252:4600-4606. [PubMed: 17603]

24. Liu TC, Korotchkina LG, Hyatt SL, Vettakkorumakankav NN, Patel MS. Spectroscopic studies of the characterization of recombinant human dihydrolipoamide dehydrogenase and its site-directed mutants. J Biol Chem 1995;270:15545-15550. [PubMed: 7797549]

25. Reed LJ, Koike M, Levitch ME, Leach FR. Studies on the nature and reactions of protein-bound lipoic acid. J Biol Chem 1958;232:143-158. [PubMed: 13549405]

26. Patel, MS.; Hong, YS. Lipoic acid as an antioxidant: Methods in Molecular Biology. Humana Press Inc; Totowa, NJ: 1998.

27. Mossessova E, Lima CD. Ulp1-SUMO crystal structure and genetic analysis reveal conserved interactions and a regulatory element essential for cell growth in yeast. Mol Cell 2000;5:865-876. [PubMed: 10882122]

28. Otwinowski Z, Minor W. Methods Enzymology 1997;276:307-326.

29. Collaborative Computational Project N. The CCP4 suite: programs for protein crystallography. Acta Crystallogr D Biol Crystallogr 1994;50:760-763. [PubMed: 15299374]

30. Brunger AT, Adams PD, Clore GM, DeLano WL, Gros P, Grosse-Kunstleve RW, Jiang JS, Kuszewski J, Nilges M, Pannu NS, Read RJ, Rice LM, Simonson T, Warren GL. Crystallography \& NMR system: A new software suite for macromolecular structure determination. Acta Crystallogr D Biol Crystallogr 1998;54:905-921. [PubMed: 9757107]

31. Jones TA, Zou JY, Cowan SW, Kjeldgaard M. Improved methods for building protein models in electron density maps and the location of errors in these models. Acta Crystallogr A 1991;47(Pt 2): 110-119. [PubMed: 2025413]

32. Brautigam CA, Chuang JL, Tomchick DR, Machius M, Chuang DT. Crystal structure of human dihydrolipoamide dehydrogenase: NAD+/NADH binding and the structural basis of disease-causing mutations. J Mol Biol 2005;350:543-552. [PubMed: 15946682]

33. Massey V, Gibson QH, Veeger C. Intermediates in the catalytic action of lipoyl dehydrogenase (diaphorase). Biochem J 1960;77:341-351. [PubMed: 13767908]

34. Reed JK. Studies on the kinetic mechanism of lipoamide dehydrogenase from rat liver mitochondria. J Biol Chem 1973;248:4834-4839. [PubMed: 4352410]

35. Cleland WW. The kinetics of enzyme-catalyzed reactions with two or more substrates or products. II. Inhibition: nomenclature and theory. Biochim Biophys Acta 1963;67:173-187. [PubMed: 14021668]

36. Argyrou A, Jin L, Siconilfi-Baez L, Angeletti RH, Blanchard JS. Proteome-wide profiling of isoniazid targets in Mycobacterium tuberculosis. Biochemistry 2006;45:13947-13953. [PubMed: 17115689]

37. Nathan C. Microbiology. An antibiotic mimics immunity. Science 2008;322:1337-1338. [PubMed: 19039126]

38. Rhee KY, Erdjument-Bromage H, Tempst P, Nathan CF. S-nitroso proteome of Mycobacterium tuberculosis: Enzymes of intermediary metabolism and antioxidant defense. Proc Natl Acad Sci U S A 2005;102:467-472. [PubMed: 15626759]

39. Smith AW, Roche H, Trombe MC, Briles DE, Hakansson A. Characterization of the dihydrolipoamide dehydrogenase from Streptococcus pneumoniae and its role in pneumococcal infection. Mol Microbiol 2002;44:431-448. [PubMed: 11972781] 
40. Deghmane AE, Soualhine H, Bach H, Sendide K, Itoh S, Tam A, Noubir S, Talal A, Lo R, Toyoshima S, Av-Gay Y, Hmama Z. Lipoamide dehydrogenase mediates retention of coronin-1 on BCG vacuoles, leading to arrest in phagosome maturation. J Cell Sci 2007;120:2796-2806. [PubMed: 17652161]

41. Danson MJ. Dihydrolipoamide dehydrogenase: a 'new' function for an old enzyme? Biochem Soc Trans 1988;16:87-89. [PubMed: 3131165]

42. Viode C, Bettache N, Cenas N, Krauth-Siegel RL, Chauviere G, Bakalara N, Perie J. Enzymatic reduction studies of nitroheterocycles. Biochem Pharmacol 1999;57:549-557. [PubMed: 9952319]

43. Herbert M, Kraiss A, Hilpert AK, Schlor S, Reidl J. Aerobic growth deficient Haemophilus influenzae mutants are non-virulent: implications on metabolism. Int J Med Microbiol 2003;293:145-152. [PubMed: 12868651]

44. O'Riordan M, Moors MA, Portnoy DA. Listeria intracellular growth and virulence require hostderived lipoic acid. Science 2003;302:462-464. [PubMed: 14564012]

45. Delano, WL. The PyMOL molecular graphics system. DeLano Scientific; San Carlos, California, USA: 2002. 


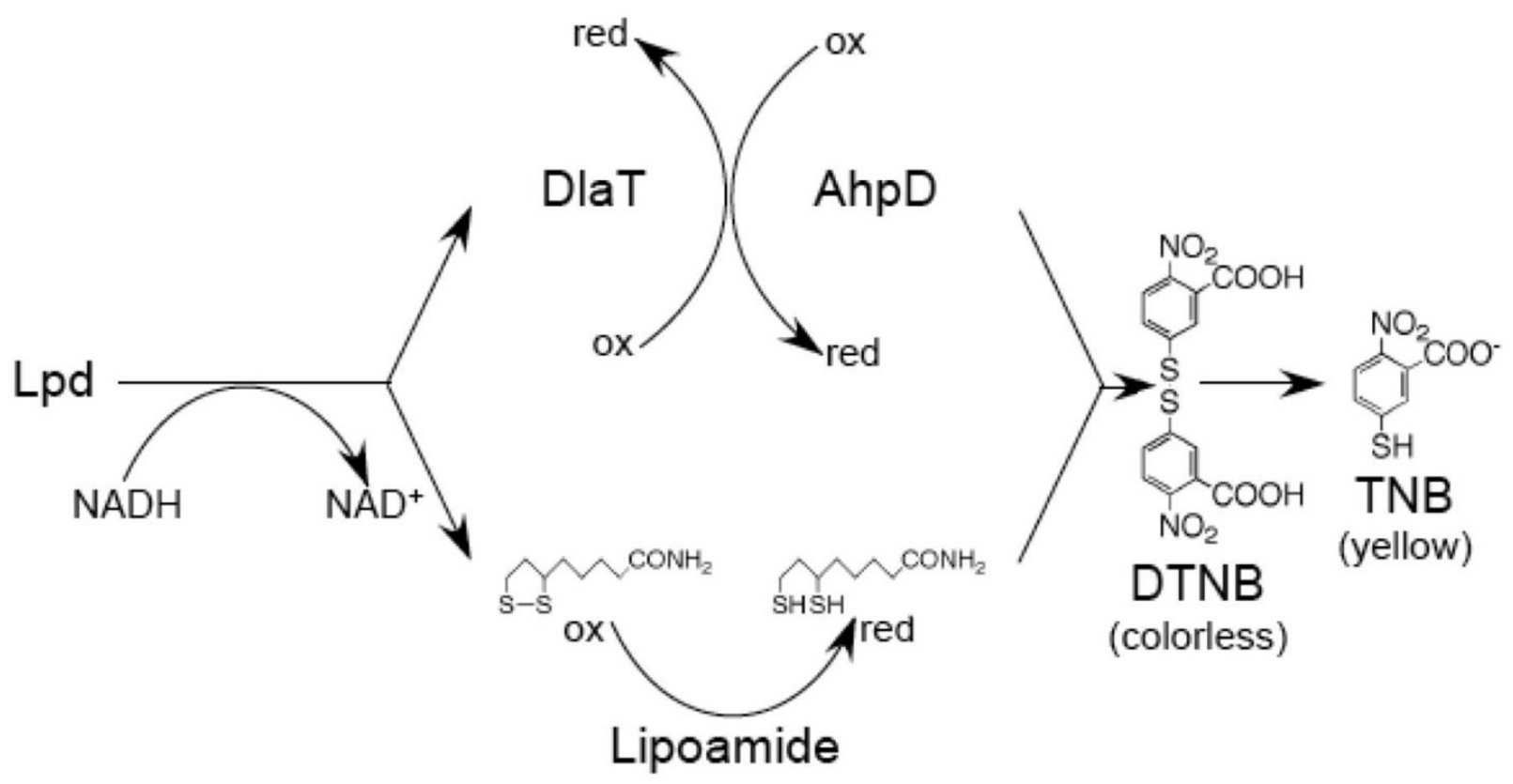

FIGURE 1.

Schematic representation of the screening assay. Lpd reduces its substrate, lipoamide, at the expense of NADH, whether lipoamide is in solution or covalently attached to DlaT (ox, oxidized; red, reduced). Lipoamide reduces DTNB to produce yellow TNB (Lpd-alone assay). DlaT's reduced lipoamide reduces AhpD's active site Cys, which in turn reduces DTNB to produce yellow TNB (Lpd+DlaT+AhpD assay). Z' factor values for both assays were 0.890.94 . 
A
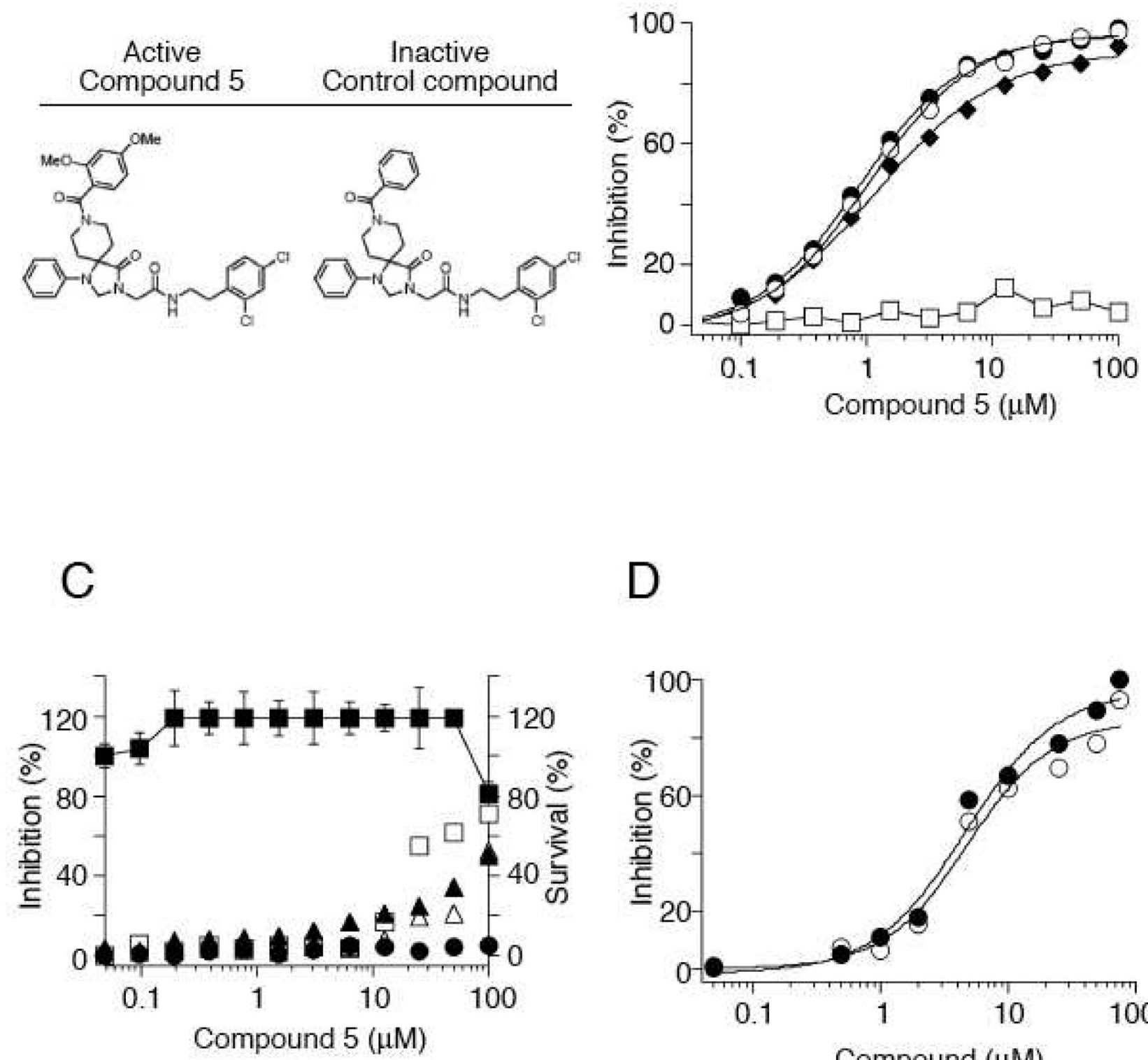

D

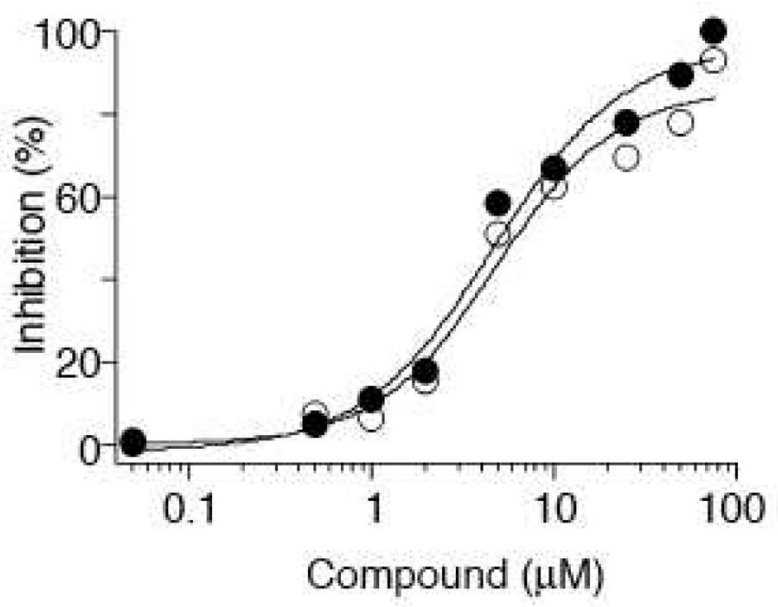

FIGURE 2.

In vitro activities of triazaspirobenzoyls. (A) Chemical structures of active (compound 5) and an inactive triazaspirobenzoyl. (B) Compound 5 but not its congener lacking dimethoxy groups (open squares) inhibits Mtb Lpd as measured by DTNB assay without (open circles) or with $100 \mu \mathrm{g} / \mathrm{ml}$ bovine serum albumin (filled circles) and by NADH oxidase assay (diamonds). (C) Compound 5 shows no inhibition against human Lpd (closed circles) and minimally inhibits bovine Lpd (open triangles), porcine PDHC (filled triangles), bovine thioredoxin reductase (open squares) and shows no toxicity against primary mouse bone marrow macrophages (filled squares). (D) Compounds $\mathbf{4}$ (open circles) and $\mathbf{5}$ (filled circles) inhibit PDHC activity in Mtb lysates. 

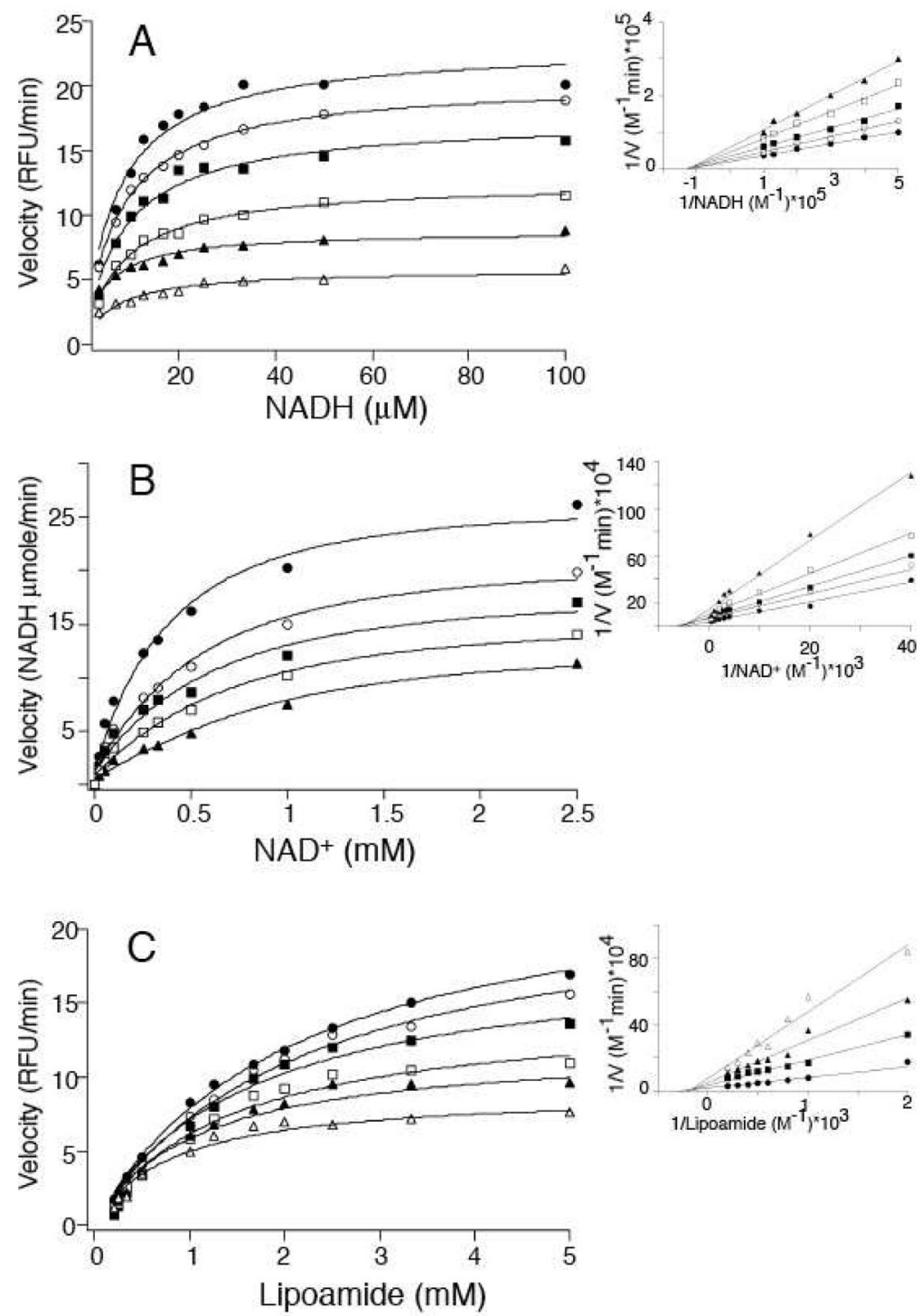

FIGURE 3.

Compound 5 is noncompetitive against NADH (A), NAD ${ }^{+}(\mathrm{B})$, and lipoamide (C). NADHlipoamide fluorimetric assay used variable NADH (in (A), 3.33 to $100 \mu \mathrm{M}$ ) or lipoamide (in (C), 0.5 to $5 \mathrm{mM}$ ) and dihydrolipoamide-NAD ${ }^{+}$spectrophotometric assay used variable $\mathrm{NAD}^{+}$(in (B) $25 \mu \mathrm{M}$ to $2.5 \mathrm{mM}$ ) without inhibitor (filled circles) or with increasing compound 5 [in (A), $10 \mathrm{nM}$, open circles; $300 \mathrm{nM}$, filled squares; $600 \mathrm{nM}$, open squares; $900 \mathrm{nM}$, filled triangles; $2 \mu \mathrm{M}$, open triangles; in (B), $1.2 \mu \mathrm{M}$, open circles; $2 \mu \mathrm{M}$, filled squares; $4 \mu \mathrm{M}$, open squares; $8 \mu \mathrm{M}$, filled triangles; in (C), $10 \mathrm{nM}$, open circles; $100 \mathrm{nM}$, filled squares; $300 \mathrm{nM}$, open squares; $900 \mathrm{nM}$, filled triangles; $1.2 \mu \mathrm{M}$, open triangles]. Data were fitted in Prism to a nonlinear regression function for noncompetitive inhibition. Insets show double-reciprocal plots. 

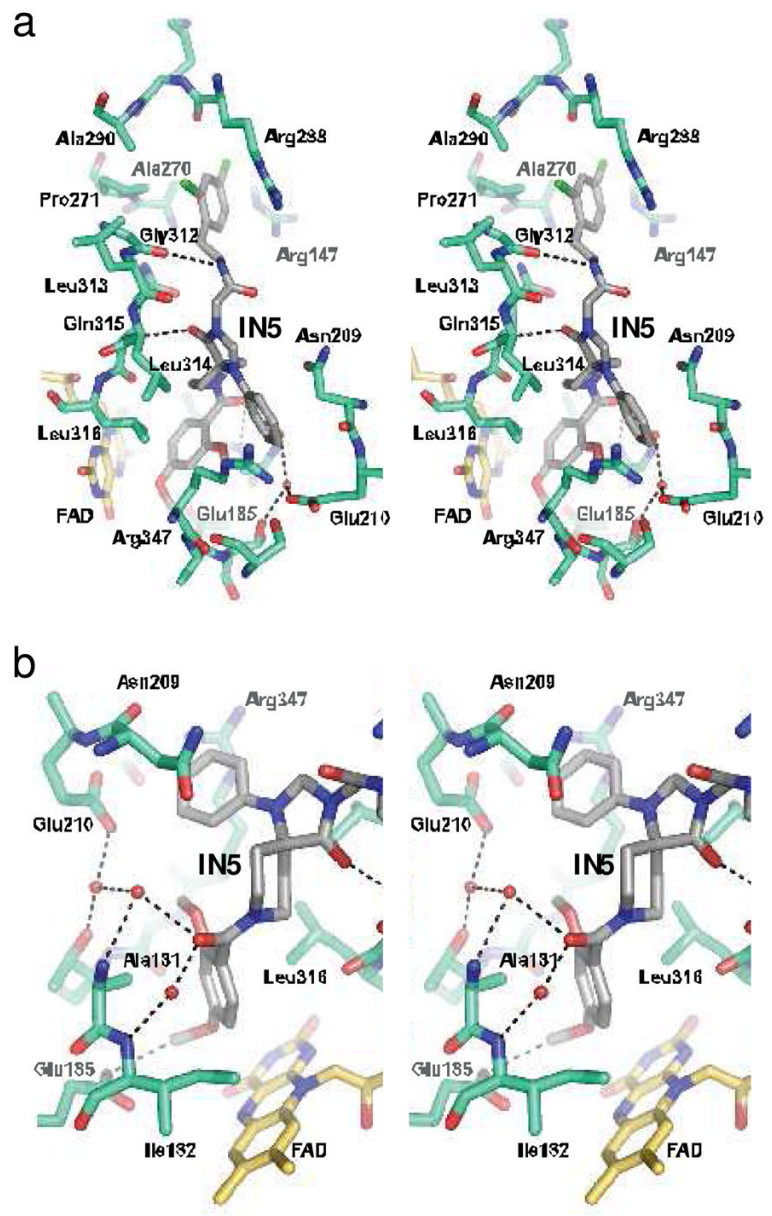

C

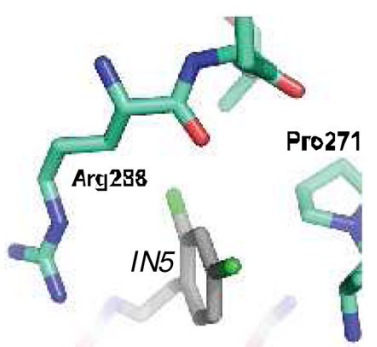

Conformer d

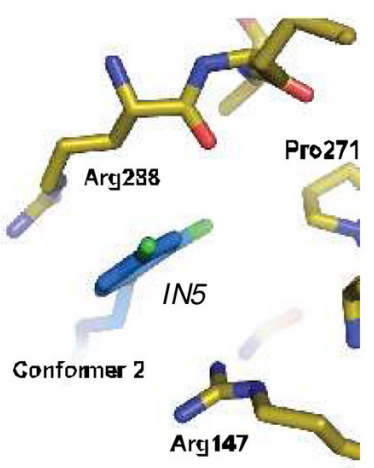

FIGURE 4.

Schematic diagram of the complex between Mtb Lpd and compound 5. (A), Stereo diagram of the structure of compound $\mathbf{5}$ (conformer 1) bound to Lpd (protomer A) with bonds and atoms shown in stick representation and color-coded with FAD carbon atoms in yellow, protein carbon atoms in blue, and compound $\mathbf{5}$ (IN5) atoms in grey. Nitrogen atoms are dark blue and oxygen atoms are red. Amino acid side chains are indicated by three-letter amino acid code and numbered. Potential hydrogen bonding interactions are shown by dashed lines. Selected water molecules that mediate contacts to compound $\mathbf{5}$ are shown as red spheres. (B) Stereo diagram of an alternate close-up view of the structure of compound $\mathbf{5}$ (conformer 1) to illustrate interactions between the dimethoxybenzoyl ring and triazaspirophenyl core. Atoms are 
represented as in (A). (C) Structure of the dichlorophenyl ring of compound $\mathbf{5}$ as coordinated in Lpd protomer A (conformer 1). Atoms represented in (C) are color-coded as described in (A). (D) Structure of the dichlorophenyl ring of compound $\mathbf{5}$ as coordinated in Lpd protomer A (conformer 2). Atoms represented in (D) are color-coded with protein carbon atoms in yellow and compound $\mathbf{5}$ carbon atoms in dark blue. All depictions of the Lpd structure were generated using PyMol (45). 
A

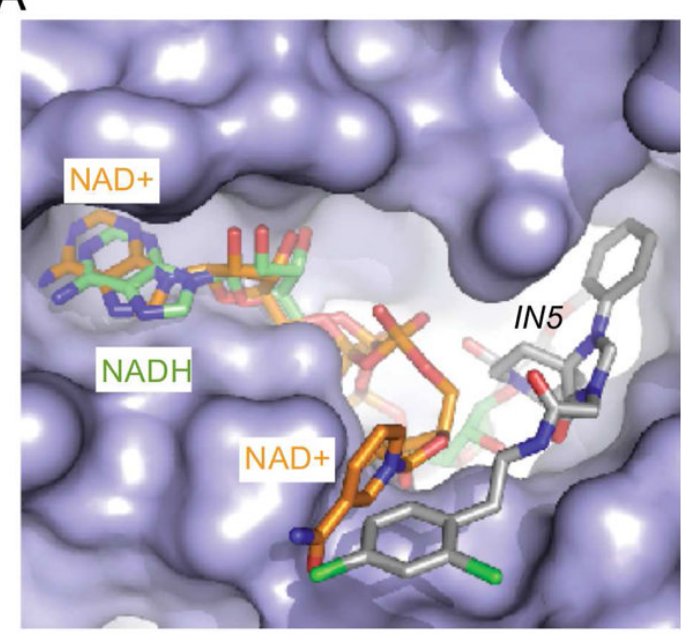

C

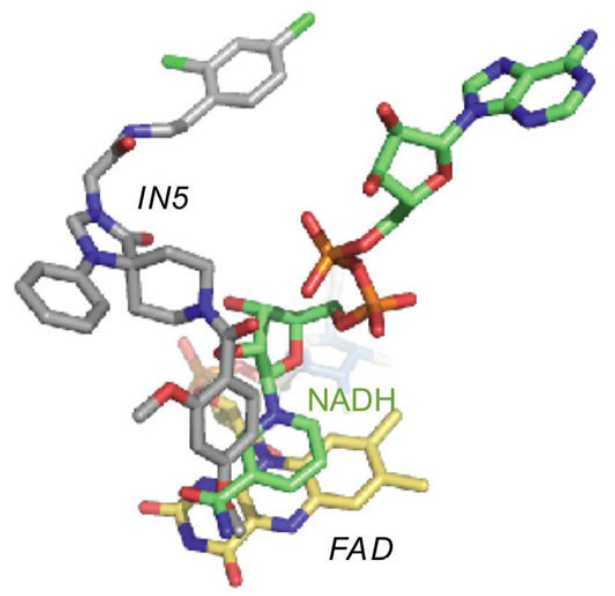

B

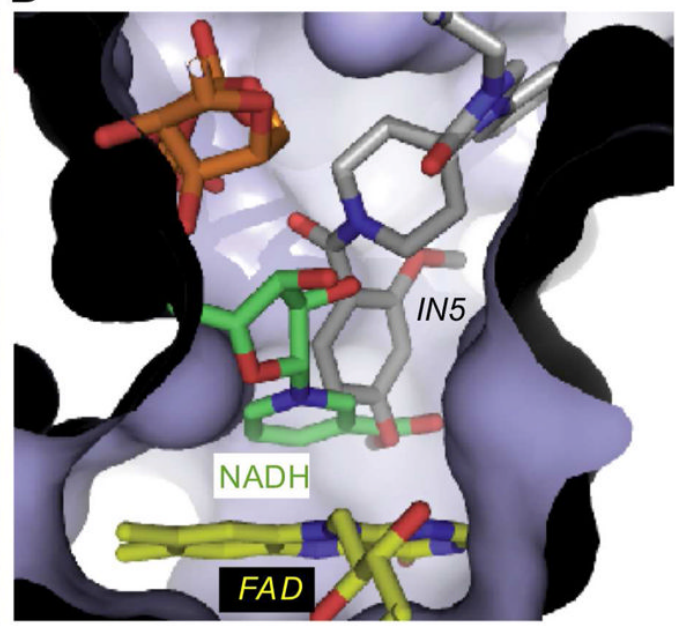

D

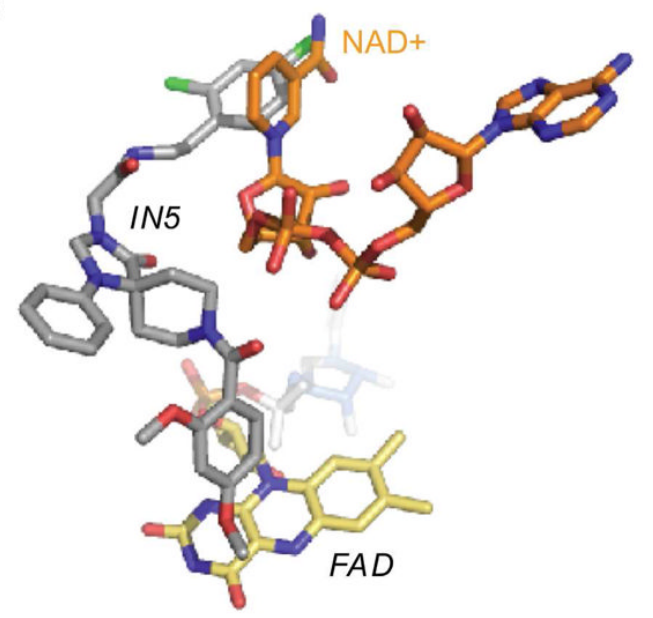

FIGURE 5.

Compound 5 partially overlaps with $\mathrm{NAD}^{+} / \mathrm{NADH}$ co-factors. (A) Surface representation of Mtb Lpd in complex with compound 5 (conformer 1) with $\mathrm{NAD}^{+}$and NADH co-factors superimposed on the structure as obtained by aligning human Lpd structures in complex with $\mathrm{NAD}^{+}$(PDB 1ZMC) and NADH (PDB 1ZMD) (32). The Lpd surface pocket that coordinates the adenosine monophosphate moiety of $\mathrm{NAD}^{+} / \mathrm{NADH}$ is highly conserved across evolution. $\mathrm{NAD}^{+}$is labeled and shown with carbon atoms in orange, NADH is labeled with carbon atoms in green, and compound 5 (IN5) is labeled with carbon atoms in grey. (B) As in (A), but a close-up view of the overlap between the nicotinamide ring of NADH and the dimethoxybenzoyl ring of compound $\mathbf{5}$ over the FAD co-factor. FAD carbon atoms are in yellow and carbon atoms for NADH and compound $\mathbf{5}$ are colored as in (A). (C) View of NADH, compound $\mathbf{5}$, and FAD in the absence of protein to illustrate the partial overlap between the NADH nicotinamide ring and the compound $\mathbf{5}$ dimethoxylbenzoyl ring with carbon atoms color-coded as in (A) and (B). (D) View of NAD ${ }^{+}$, compound 5, and FAD in the absence of protein to illustrate the partial overlap between the $\mathrm{NAD}^{+}$nicotinamide ring and the compound 5 dichlorophenyl ring with carbon atoms color-coded as in (A) and (B). 
TABLE 1

Data collection and refinement statistics

\begin{tabular}{|c|c|}
\hline & Lpd-Compound 5 \\
\hline \multicolumn{2}{|l|}{ Data collection ${ }^{*}$} \\
\hline Space group & $\mathrm{P} 2_{1} 2_{1} 2_{1}$ \\
\hline \multicolumn{2}{|l|}{ Cell dimensions } \\
\hline$a, b, c(\AA)$ & $83.9,98.4,123.8$ \\
\hline$\alpha, \beta, \gamma\left({ }^{\circ}\right)$ & $90,90,90$ \\
\hline Resolution $(\AA)$ & $30-2.42(2.51-2.42)$ \\
\hline Total reflections & 171989 \\
\hline Unique reflections & 39154 \\
\hline Wilson B & 37.3 \\
\hline$R_{\text {merge }}$ & $8.0(35.6)$ \\
\hline$I / \sigma I$ & $19.0(3.7)$ \\
\hline Completeness (\%) & $98.9(98.0)$ \\
\hline Redundancy & $4.4(3.6)$ \\
\hline \multicolumn{2}{|l|}{ Refinement } \\
\hline Resolution $(\AA)$ & $30-2.42(2.51-2.42)$ \\
\hline No. reflections $R_{\text {work }} / R_{\text {free }}$ & $37168 / 1942$ \\
\hline$R_{\text {work }} / R_{\text {free }}$ & $18.5(25.2) / 24.2(31.1)$ \\
\hline \multicolumn{2}{|l|}{ No. atoms } \\
\hline Protein & 6930 \\
\hline FAD & 106 \\
\hline Compound 5 & 86 \\
\hline Water & 751 \\
\hline \multicolumn{2}{|l|}{ Average $B$-factors } \\
\hline Protein (protomer A/B) & $28.2 / 28.7$ \\
\hline FAD (protomer A/B) & $19.8 / 19.0$ \\
\hline Compound $\mathbf{5}$ (protomer A/B) & $38.0 / 44.3$ \\
\hline Water & 33.0 \\
\hline \multicolumn{2}{|l|}{ R.m.s. deviations } \\
\hline Bond lengths $(\AA)$ & 0.006 \\
\hline Bond angles $\left(^{\circ}\right)$ & 1.20 \\
\hline
\end{tabular}

*ne crystal.

*Highest-resolution shell shown in parentheses. 


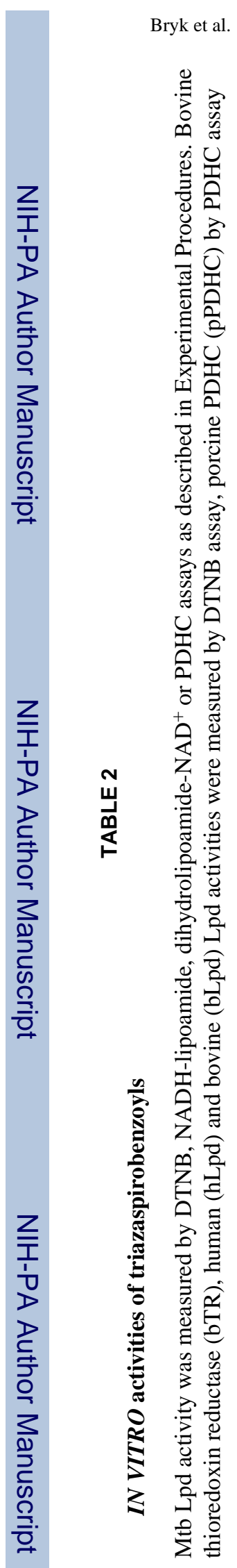

Biochemistry. Author manuscript; available in PMC 2011 March 2. 


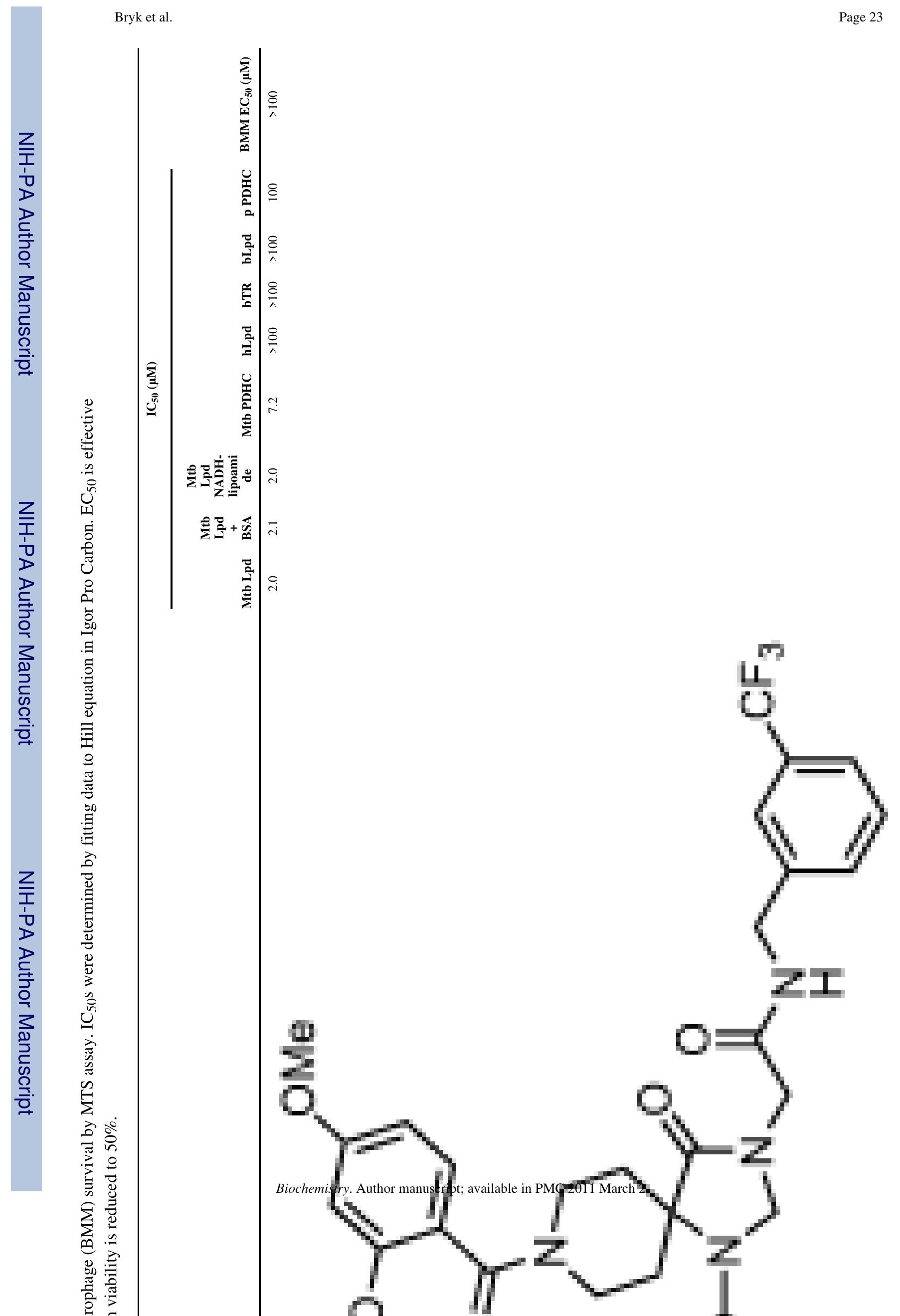




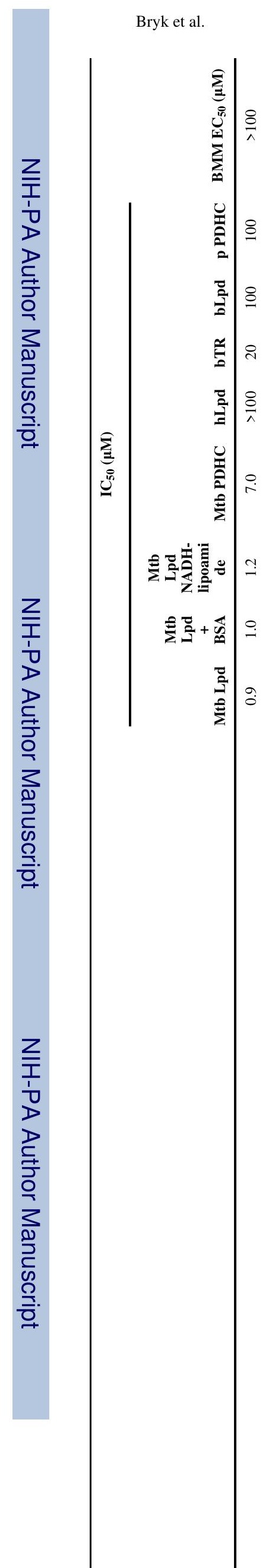

Page 24

Biochemistry. Author manuscript; available in PMC 2011 March 2. 


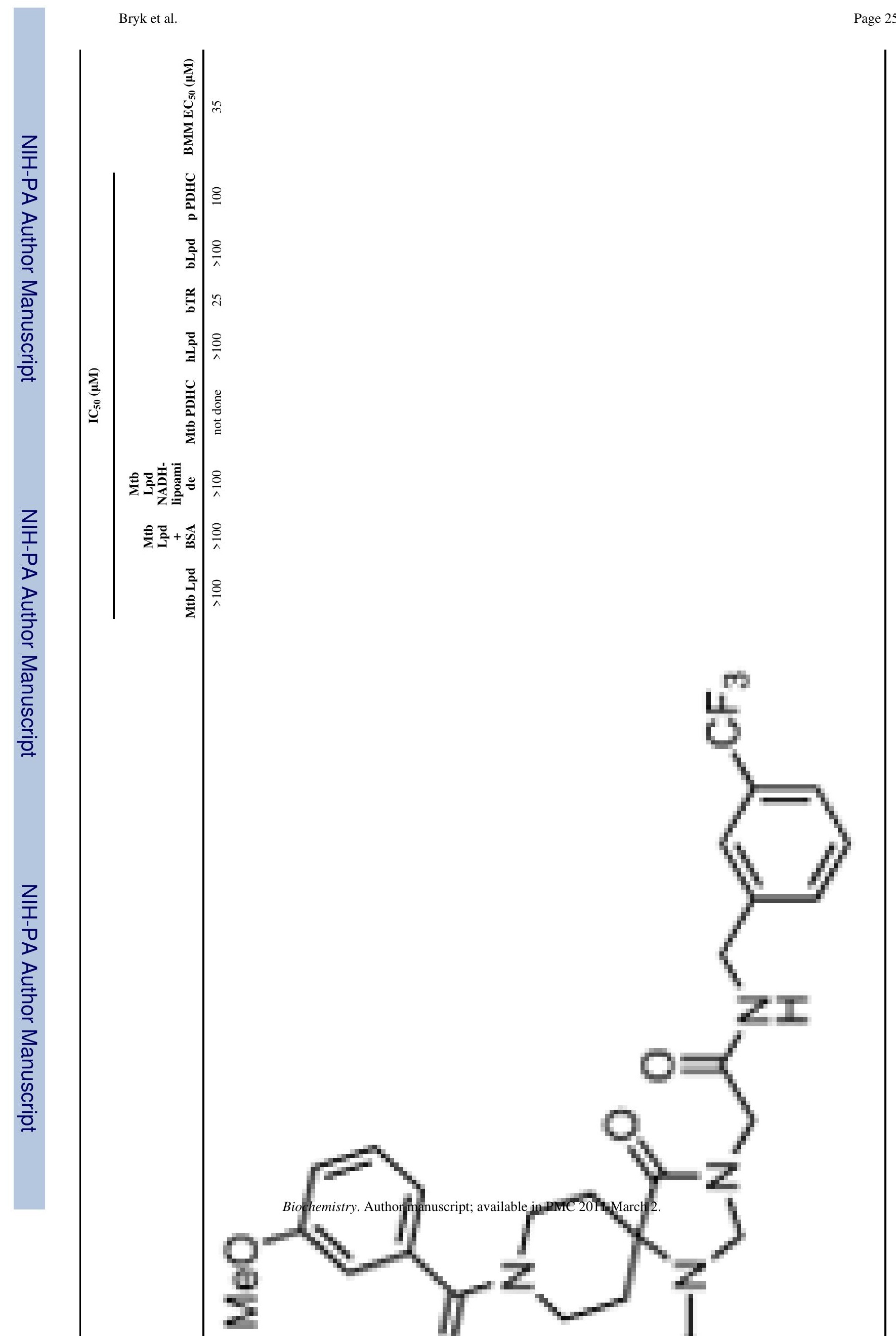


TABLE 3

Structure-activity relationship of selected triazaspirobenzoyls

Mtb Lpd activity was measured by DTNB assay. Data were fitted to Hill equation in Igor Pro Carbon to determine $\mathrm{IC}_{50}$ values.
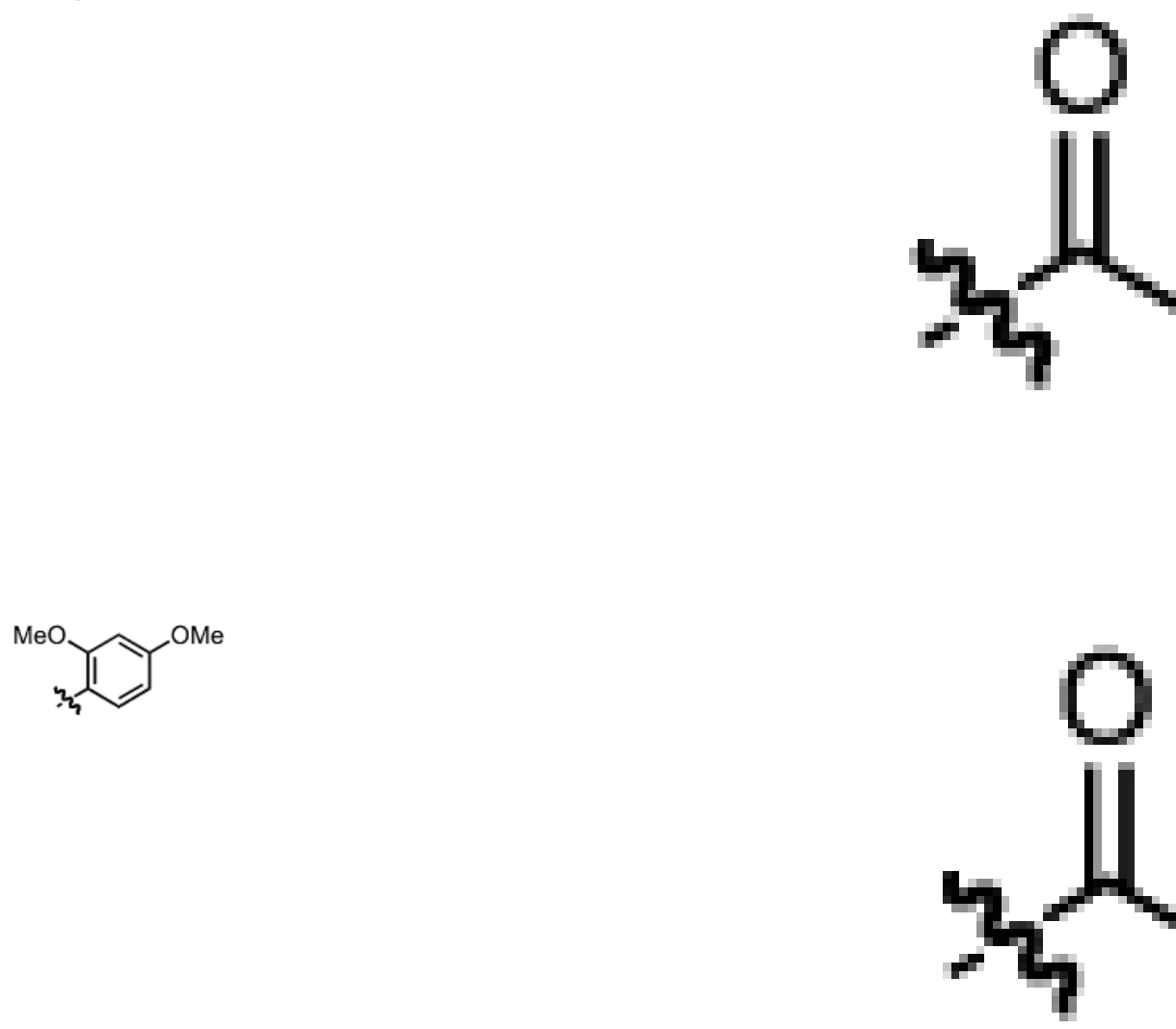
$\mathbf{R}_{1}$
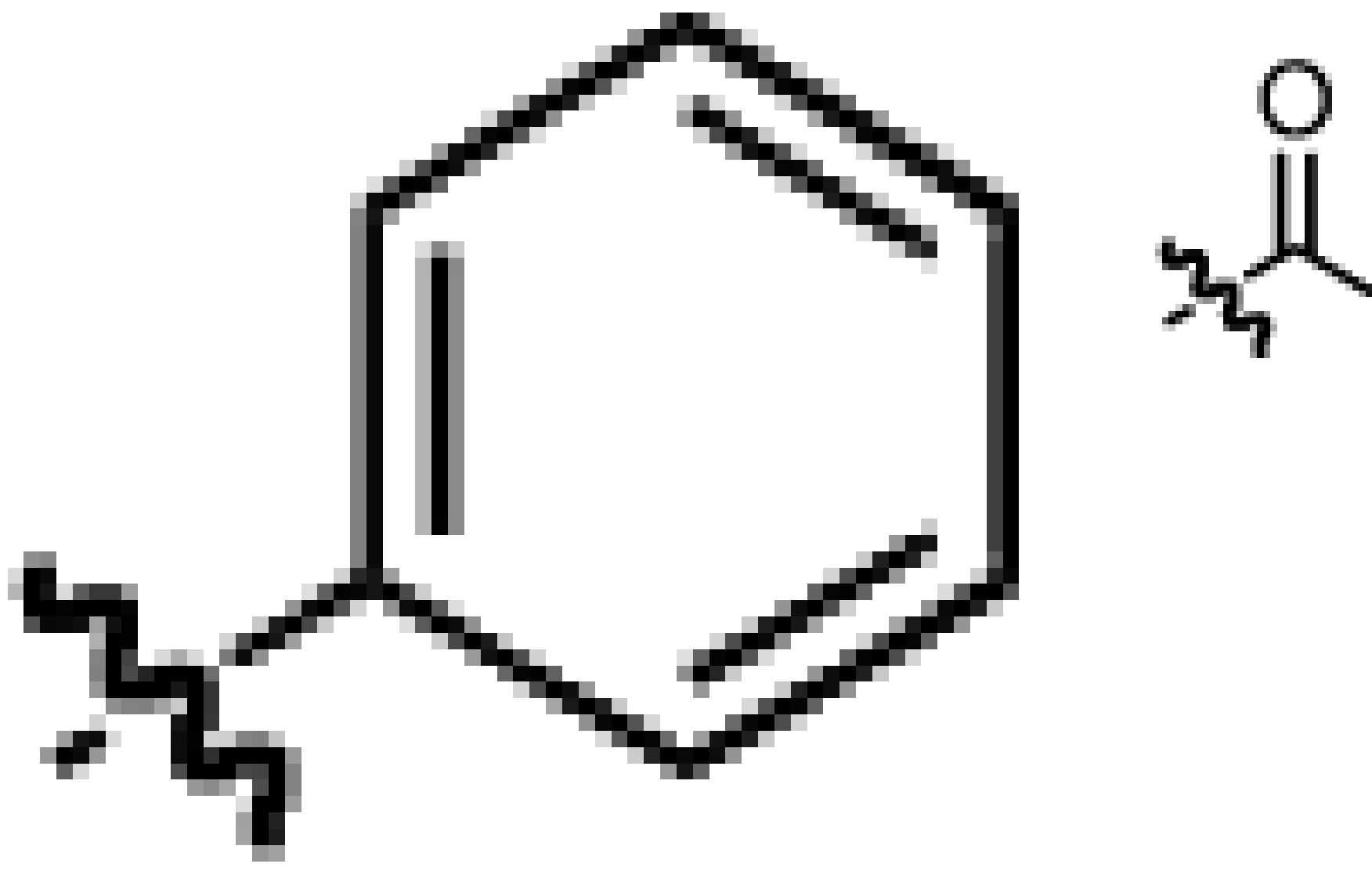<smiles>COc1cccc(OC)c1</smiles> 
$\mathbf{R}_{1}$
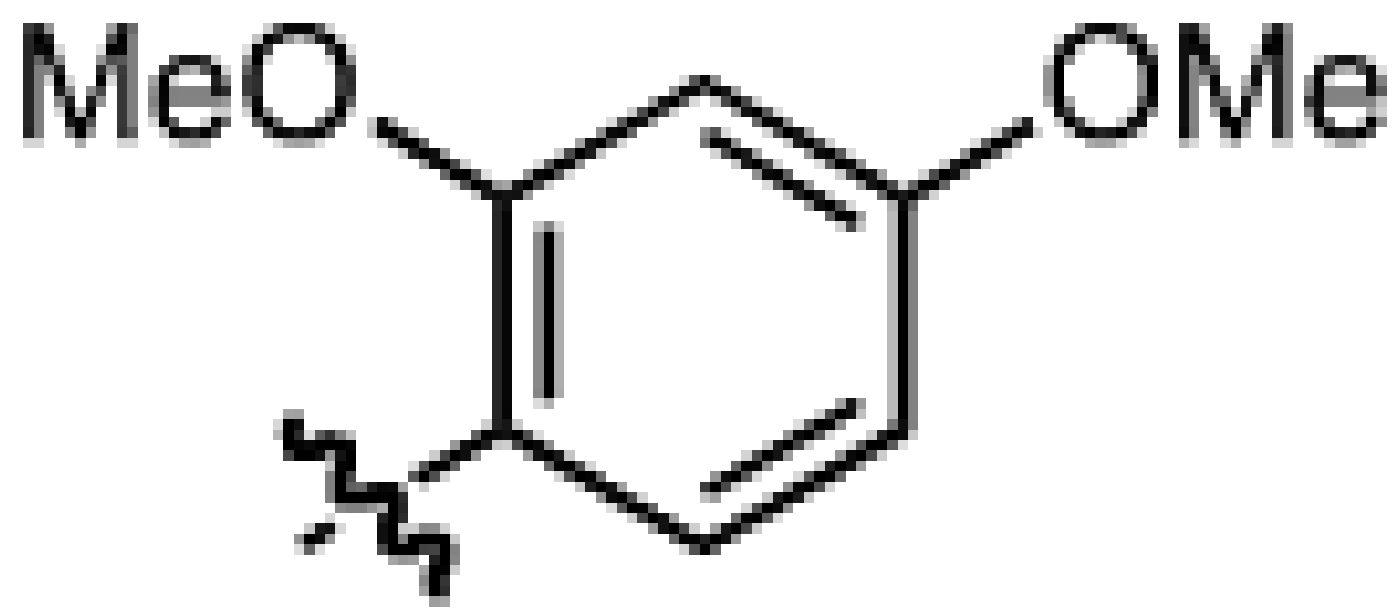

$\mathrm{MeO}$

Biochemistry. Author manuscript; available in PMC 2011 March 2. 

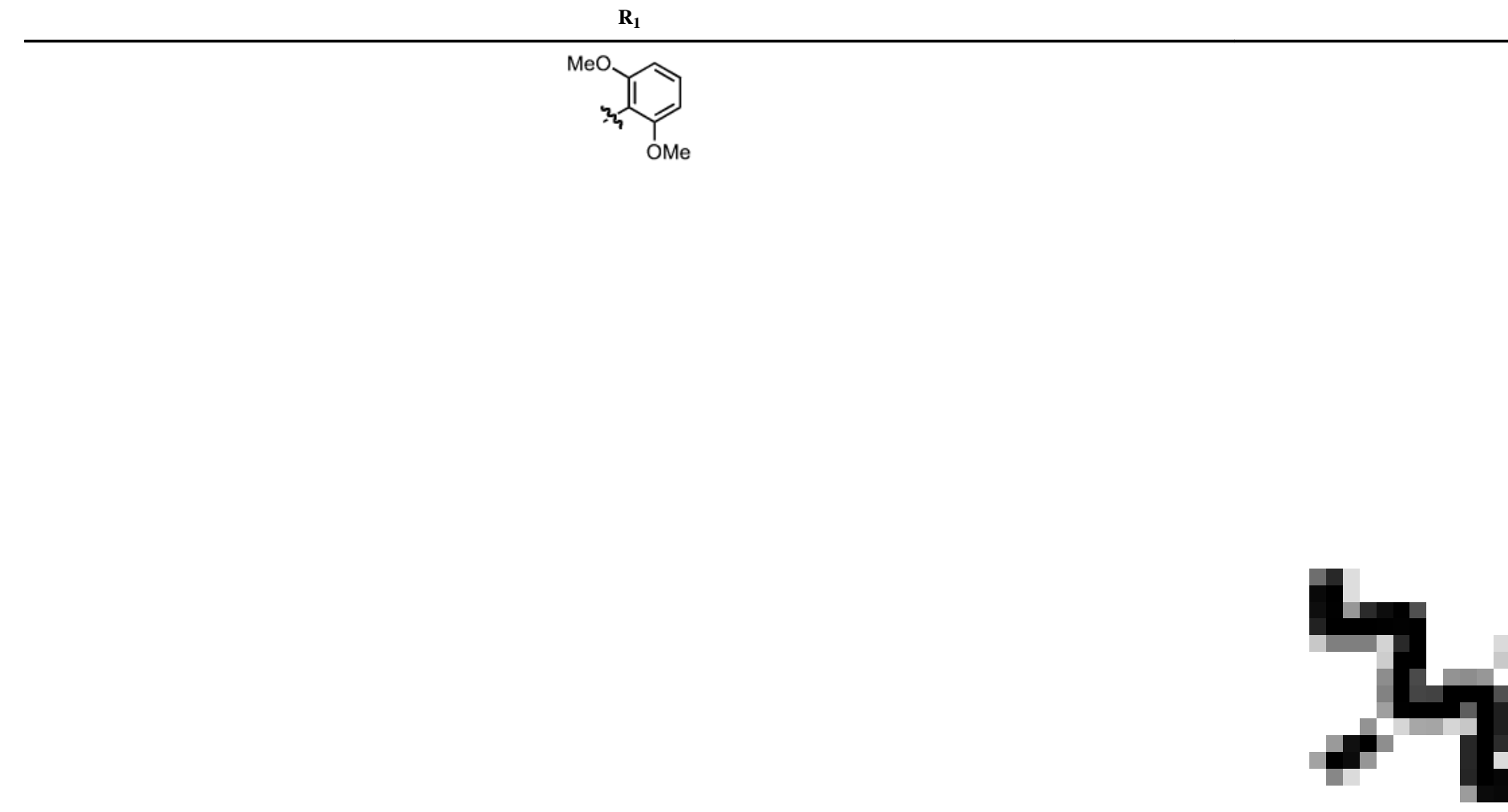
$\mathbf{R}_{1}$
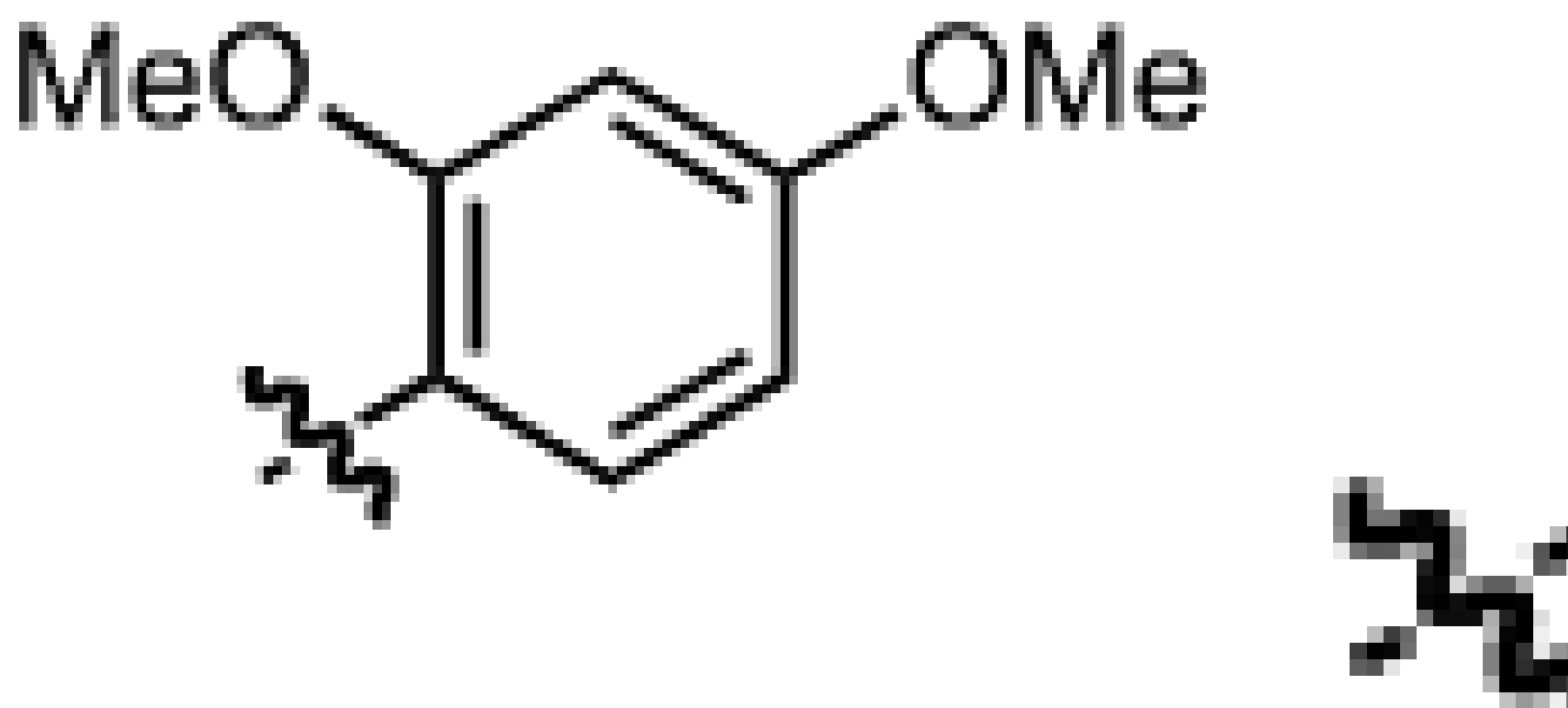

Biochemistry. Author manuscript; available in PMC 2011 March 2. 
$\mathbf{R}_{1}$

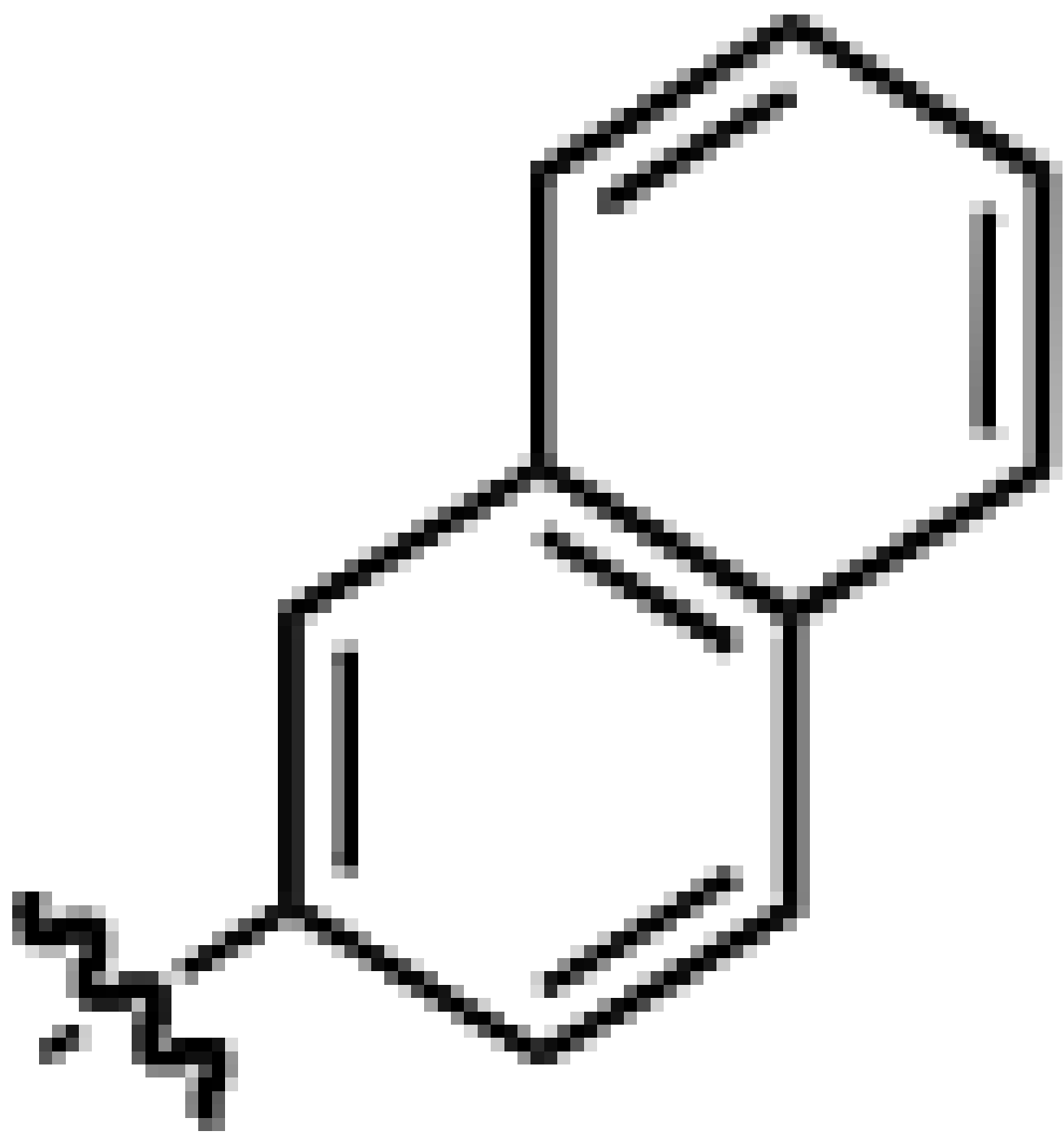

(1)

Biochemistry. Author manuscript; available in PMC 2011 March 2. 

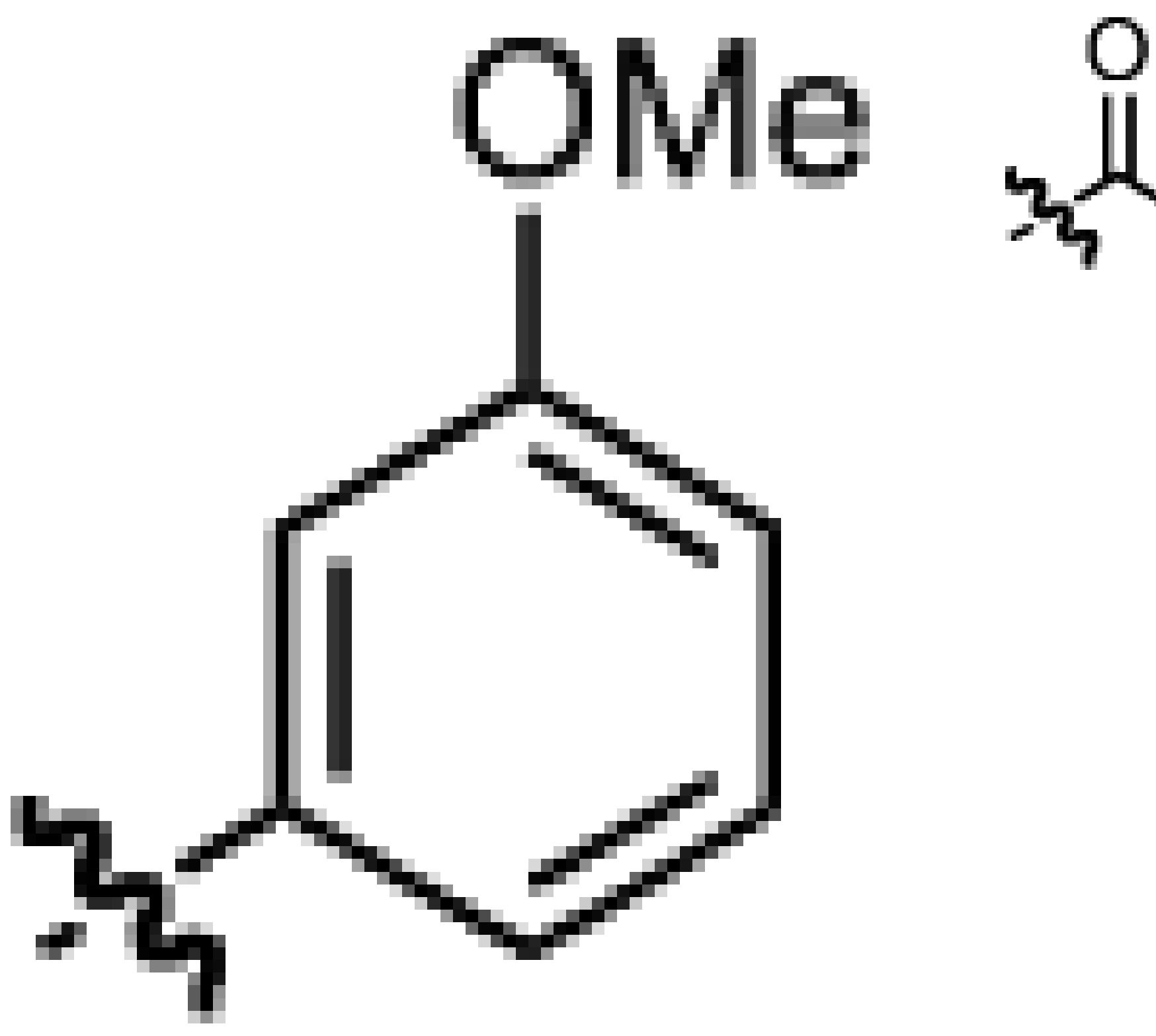
$\mathbf{R}_{1}$
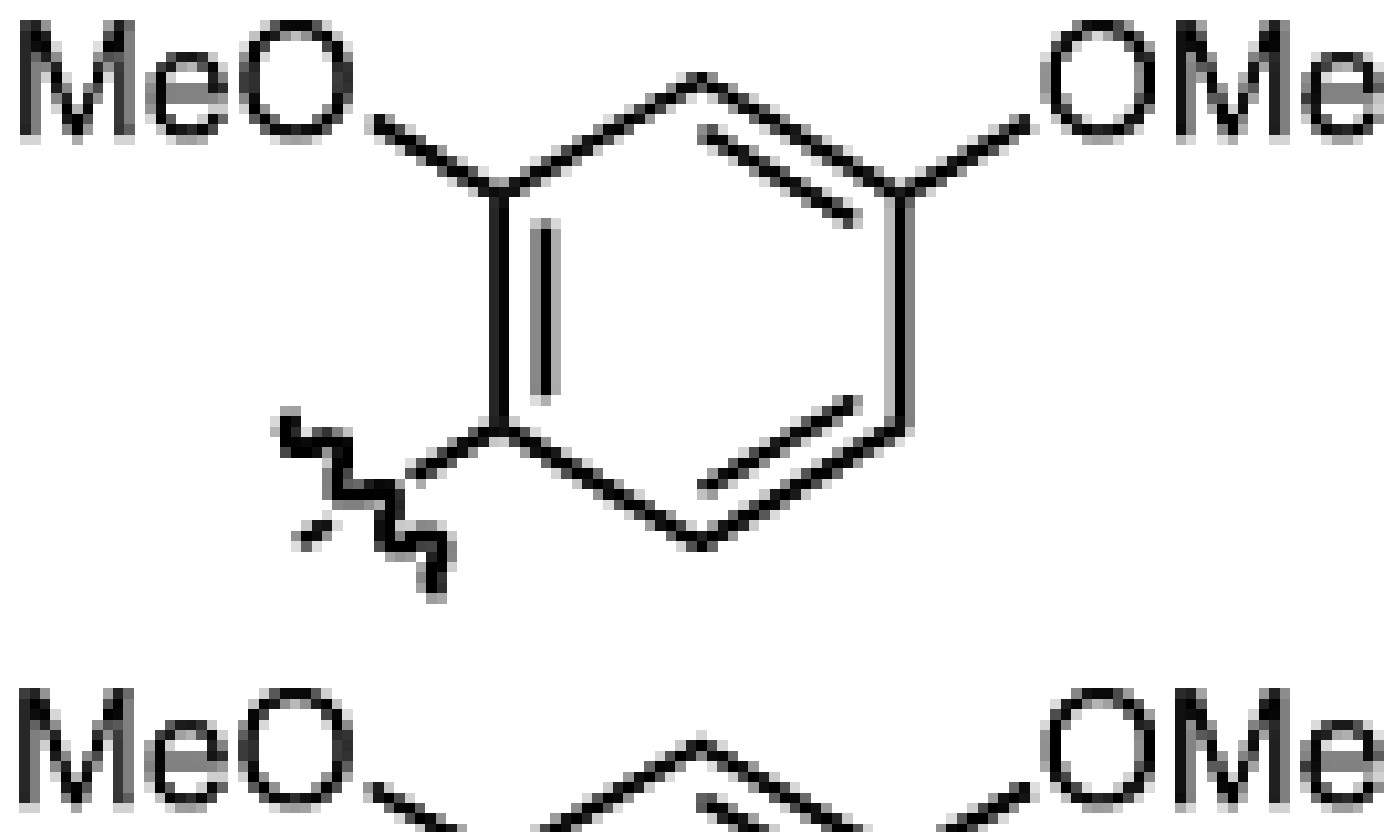


\section{TABLE 4}

\section{Activity of compound 5 against mutant Mtb Lpd proteins}

Mtb Lpd mutant proteins were generated and purified as described in Experimental Procedures. IC $_{50}$ values were determined with $100 \mathrm{nM}$ protein in DTNB assay. Red in compound $\mathbf{5}$ structure denotes crytallographically evident contacts with Mtb Lpd; blue areas indicate contacts that were lost in a mutant Mtb Lpd.

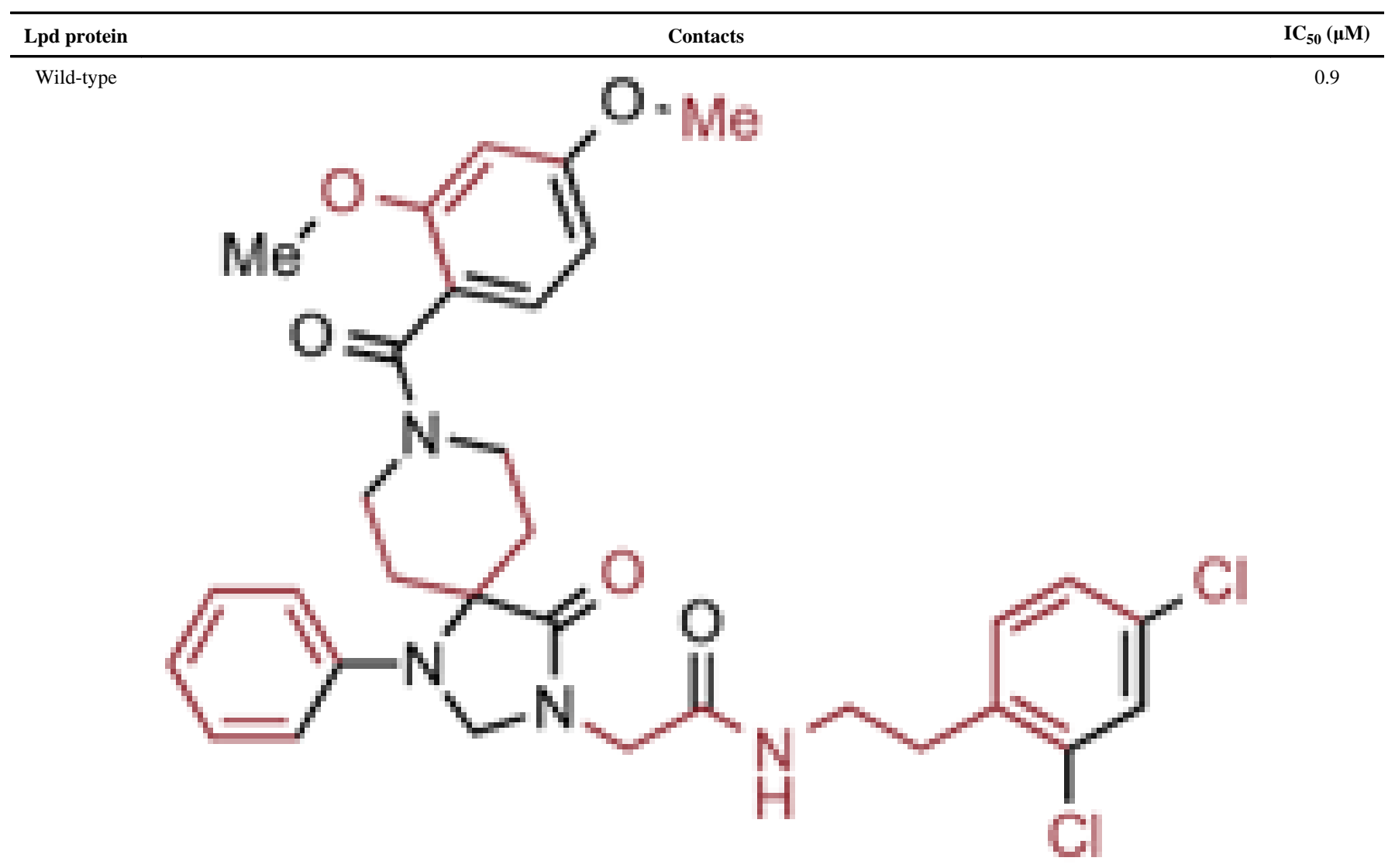




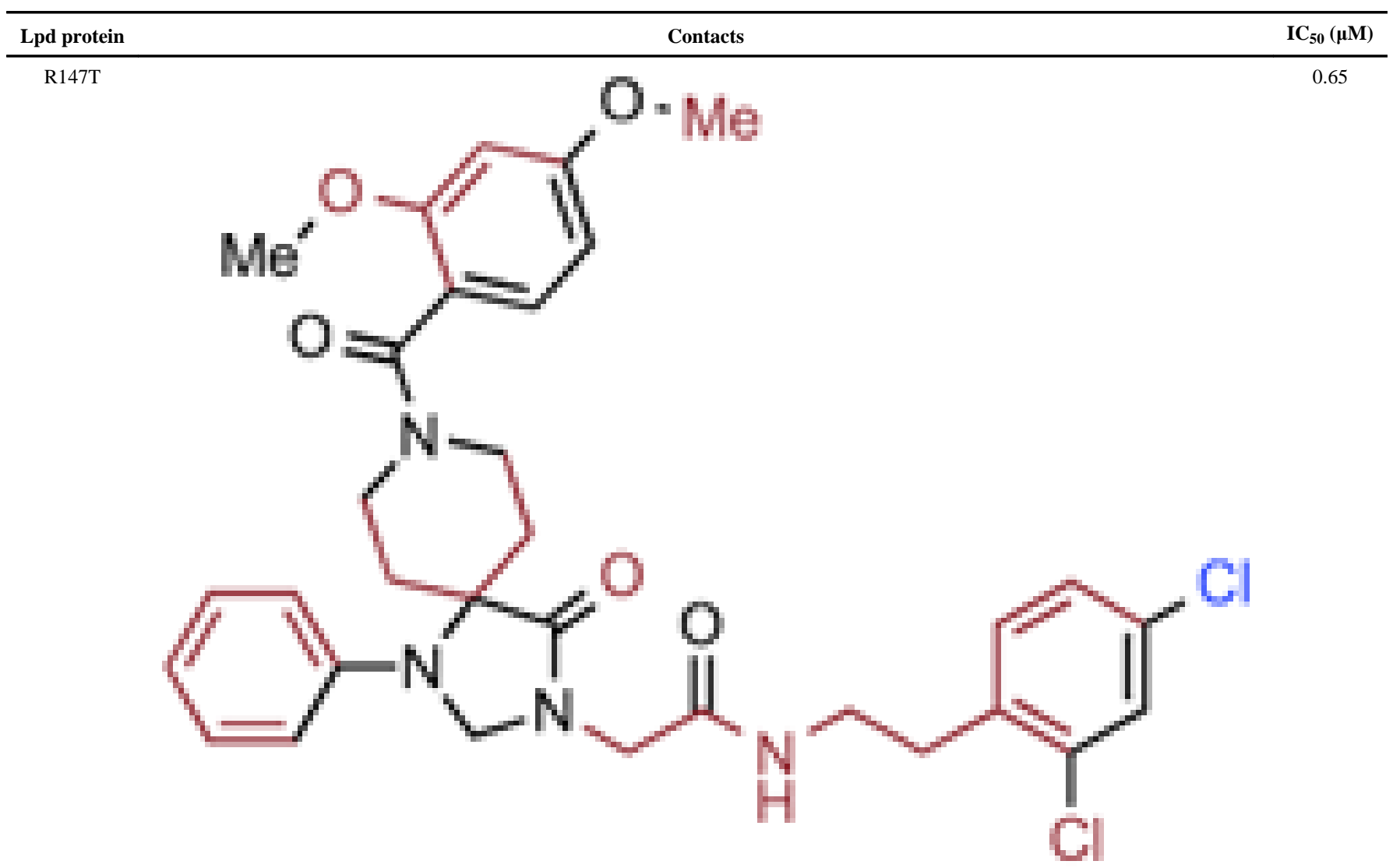




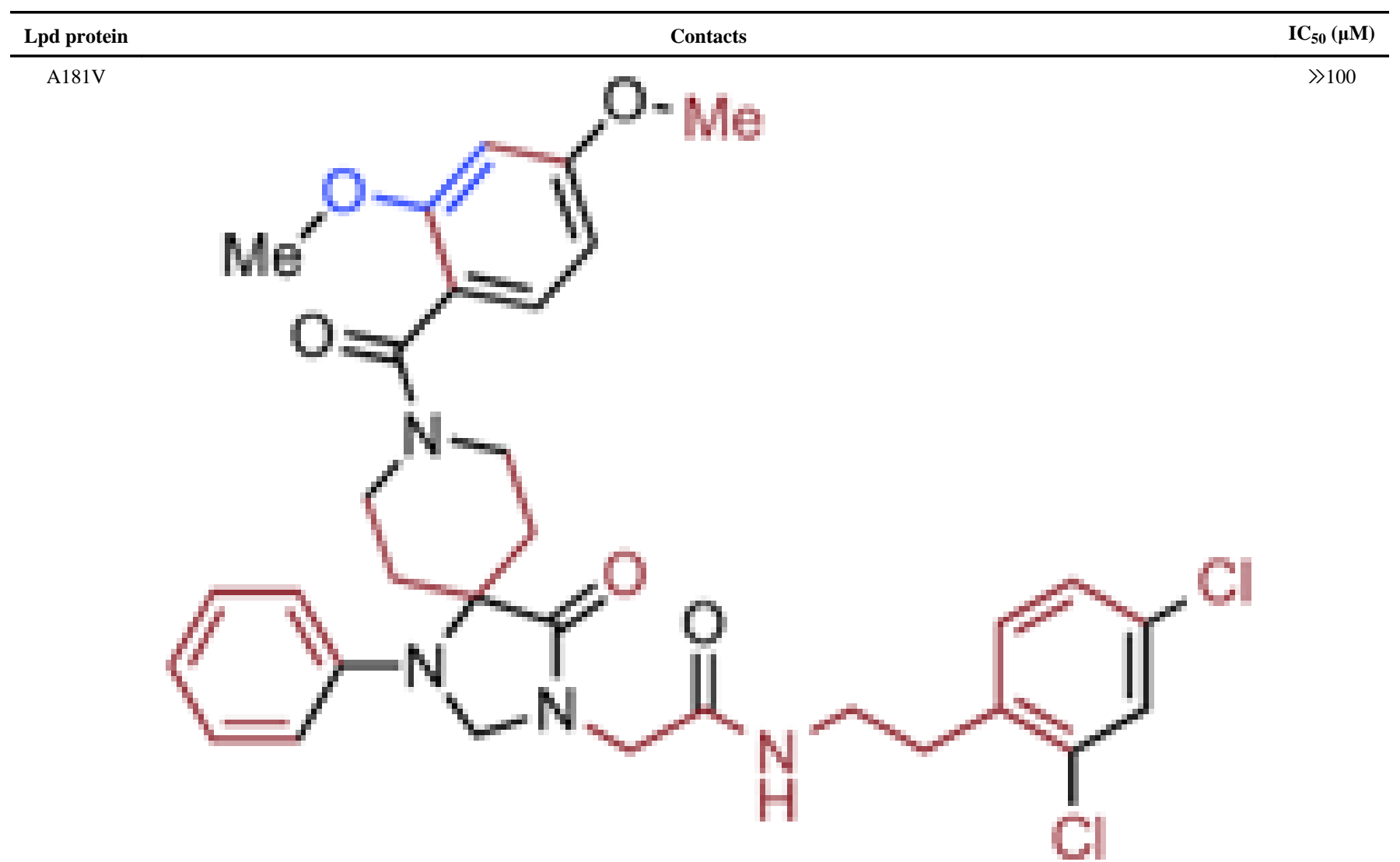

N209V

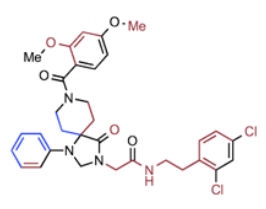




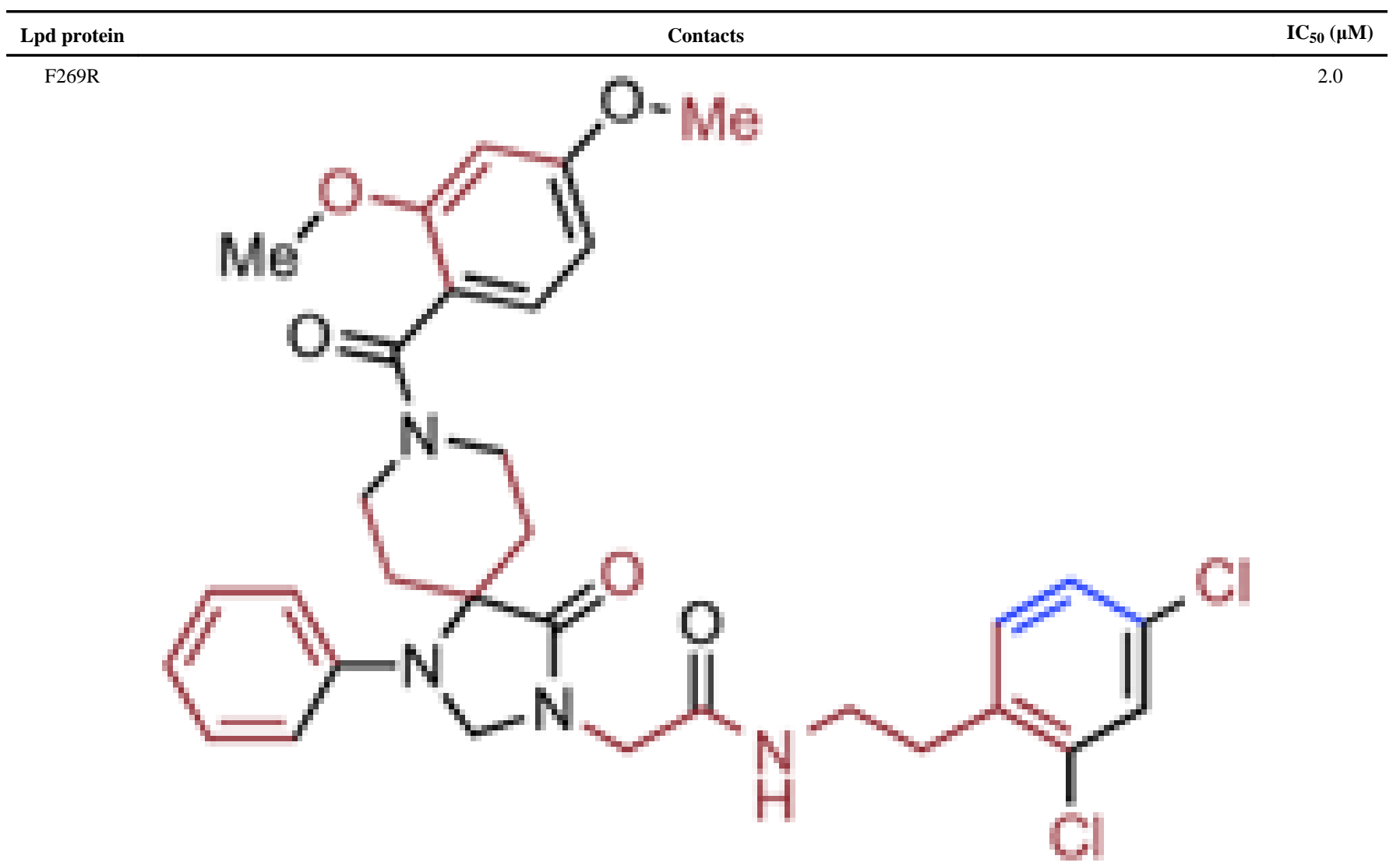




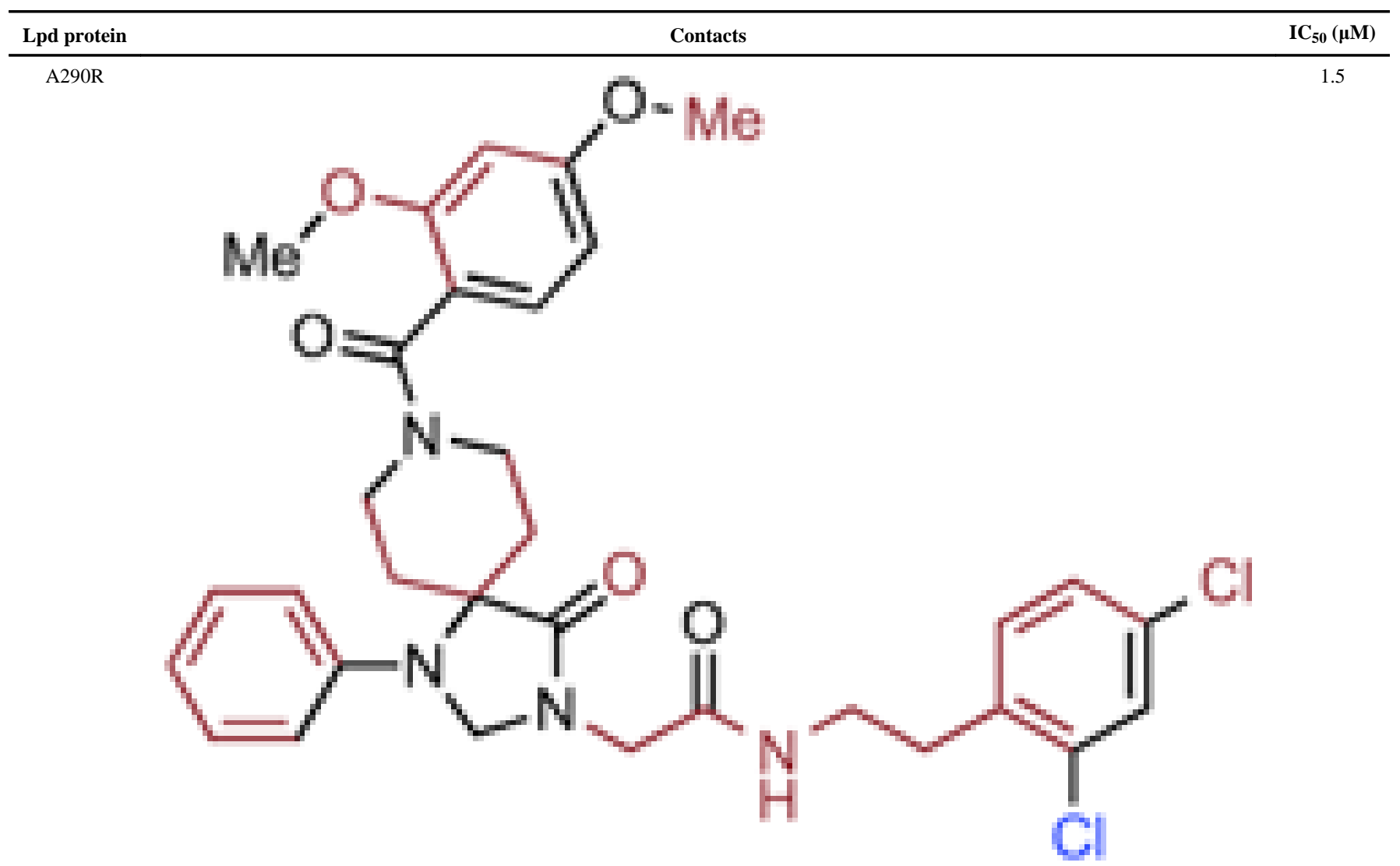




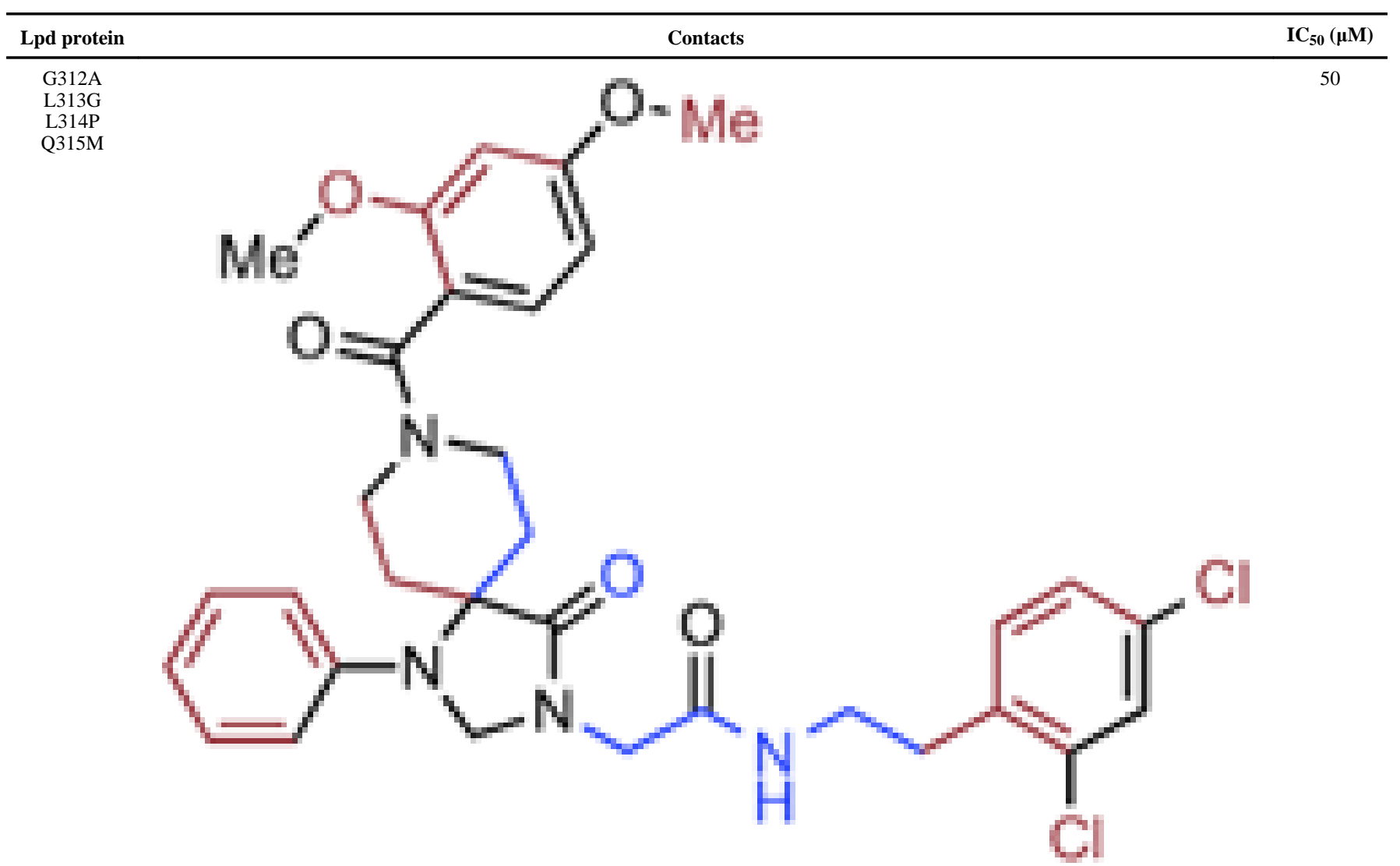




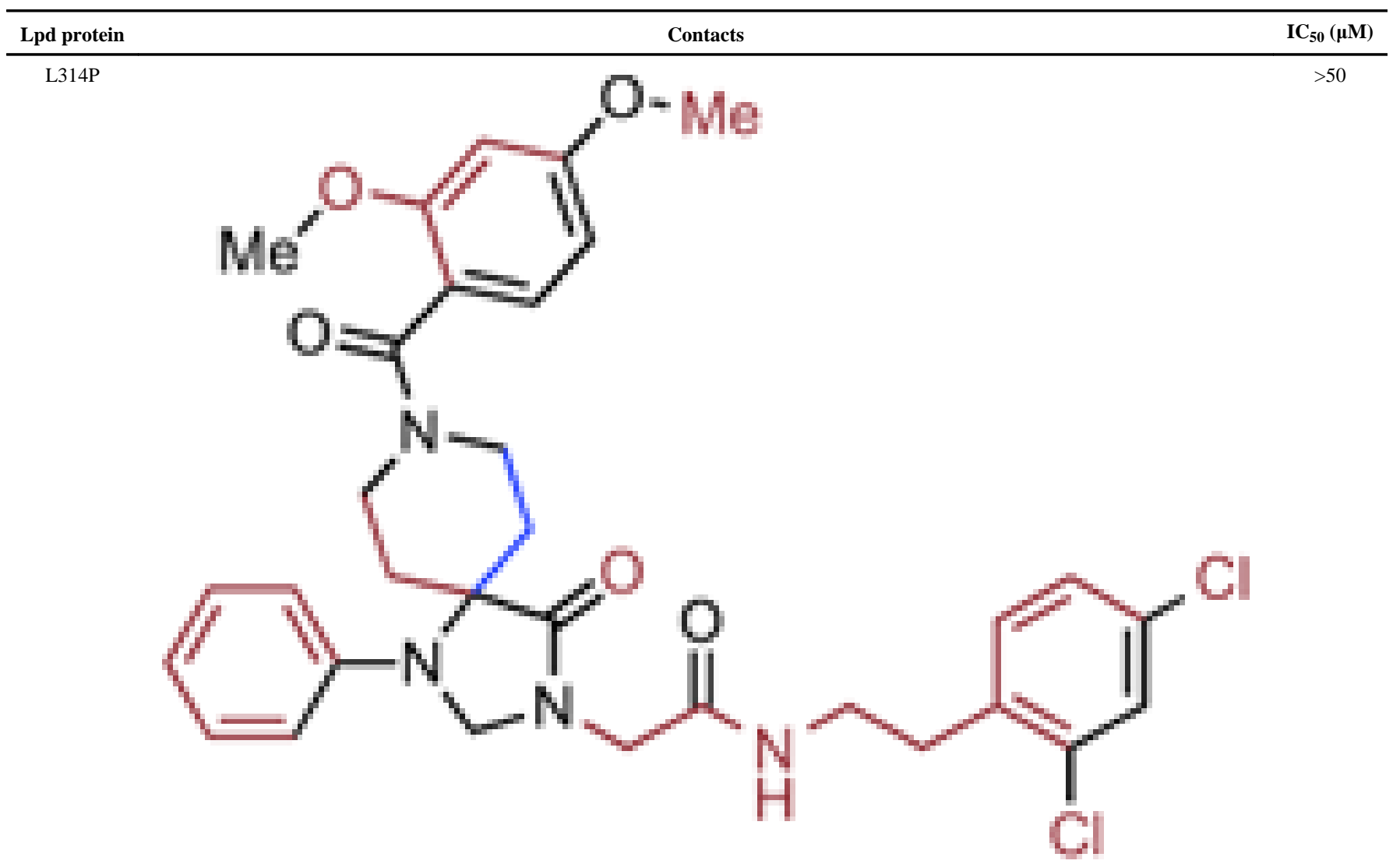

R347S

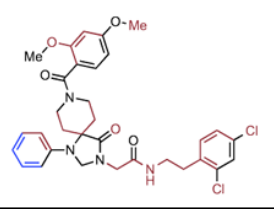

